\title{
Experimental Investigation on the Correlation between Dynamic Ultrasonic and Mechanical Properties of Sandstone Subjected to Uniaxial Compression
}

\author{
Yunjiang Sun, ${ }^{1}$ Jianping Zuo $\mathbb{D}^{1,2}$ Yue Shi, ${ }^{1}$ Zhengdai $\mathrm{Li}^{1}{ }^{1}$ Changning Mi, ${ }^{1}$ and Jinhao Wen ${ }^{1}$ \\ ${ }^{1}$ School of Mechanics and Civil Engineering, China University of Mining \& Technology (Beijing), Beijing 100083, China \\ ${ }^{2}$ State Key Laboratory of Coal Resources and Safe Mining, China University of Mining \& Technology, Beijing 100083, China \\ Correspondence should be addressed to Jianping Zuo; zjp@cumtb.edu.cn
}

Received 19 January 2021; Revised 4 February 2021; Accepted 23 February 2021; Published 9 March 2021

Academic Editor: Bin Gong

Copyright ( 2021 Yunjiang Sun et al. This is an open access article distributed under the Creative Commons Attribution License, which permits unrestricted use, distribution, and reproduction in any medium, provided the original work is properly cited.

\begin{abstract}
Ultrasonic wave velocity is effective to evaluate anisotropy property and predict rock failure. This paper investigates the correlation between dynamic ultrasonic and mechanical properties of sandstones with different buried depths subjected to uniaxial compression tests. The circumferential anisotropy and axial wave velocity of sandstone are obtained by means of ultrasonic wave velocity measurements. The mechanical properties, including Young's modulus and uniaxial compressive strength, are positively correlated with the axial $\mathrm{P}$ wave velocity. The average angles between the sandstone failure plane and the minimum and maximum wave directions are $35.8^{\circ}$ and $63.3^{\circ}$, respectively. The axial $\mathrm{P}$ wave velocity almost keeps constant, and the axial $\mathrm{S}$ wave velocity has a decreasing trend before the failure of rock specimen. In most rock samples under uniaxial compression, shear failure occurs in the middle and splitting appears near both sides. Additionally, the dynamic Young's modulus and dynamic Poisson's ratio during loading are obtained, and the negative values of the Poisson's ratio occur at the initial compression stage. Distortion and rotation of micro/mesorock structures may be responsible for the negative Poisson's ratio.
\end{abstract}

\section{Introduction}

In western China, most of the coal seams are shallowly buried and have large thicknesses. The maximum mining thickness reaches approximately $9.0 \mathrm{~m}$, which may result in very large mining pressure and overburden failure. The groundwater may flow into the mined-out area along mining-induced fissures in overburden, which will result in groundwater level dropping and surface vegetation destruction. Furthermore, the water resources in the western mining area are very scarce, which only takes up $3.7 \%$ of the total in China [1]. Generally, the height of the fractured zone is detected by drilling holes from ground surface, which cost much and can only obtain the partial area. However, the ultrasonic probing method can be used to determine physical and mechanical properties and predict the rock failure based on the ultrasonic wave velocity [2]. The ultrasonic velocity techniques are nondestructive and easily applied under both site and laboratory conditions, which have been widely used to investigate the initial defects due to geological action and the mining-induced cracks in the internal overburden [3-5]. Therefore, the ultrasonic property can be used to determine the spatial distribution of mining-induced fissures in overburden.

During the loading process, the rock cracks go through five phases: crack closure phase, elastic phase, crack stable growth phase, crack unstable growth phase, and postpeak stage [6-8]. The ultrasonic wave velocity attenuates when the wave passes through cracks in rocks, which is the basis for estimating the physical and mechanical properties [911]. Some empirical equations have been developed for predicting the uniaxial compressive strength, Young's modulus, tensile strength, shear strength, and density by using the $\mathrm{P}$ wave velocity in rocks [12-14]. Meng et al. established a correlation between the dynamic mechanical parameters of the sedimentary rock and ultrasonic wave velocity during loading [15]. Additionally, due to the uneven distribution of fissures in rocks, the anisotropic behavior of both $\mathrm{P}$ wave 

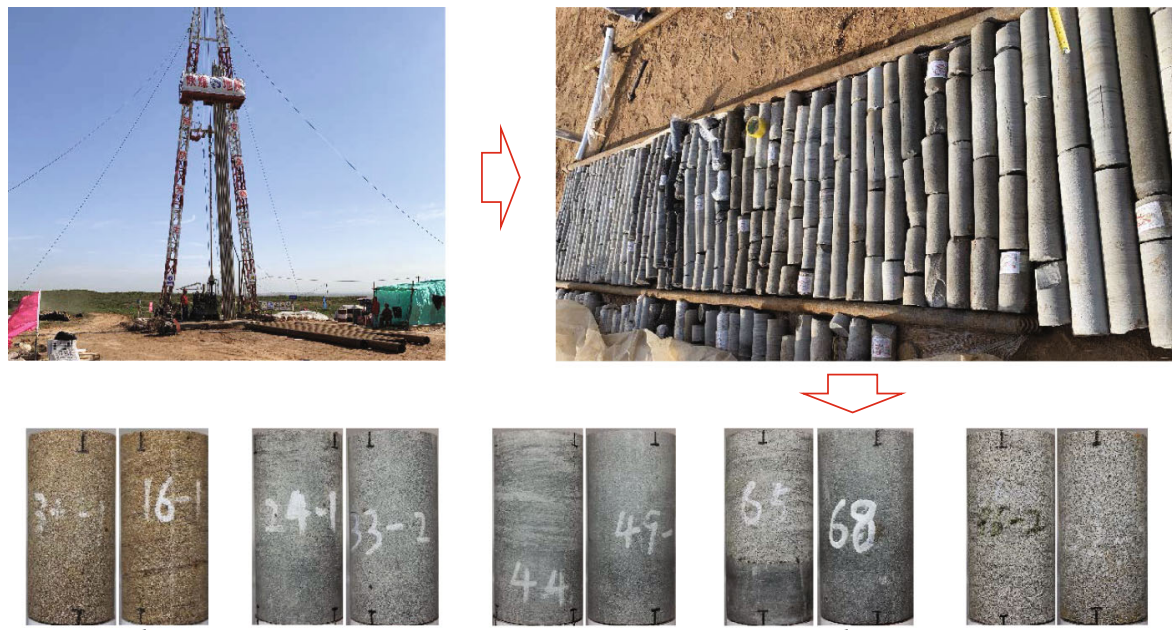

Mudstone
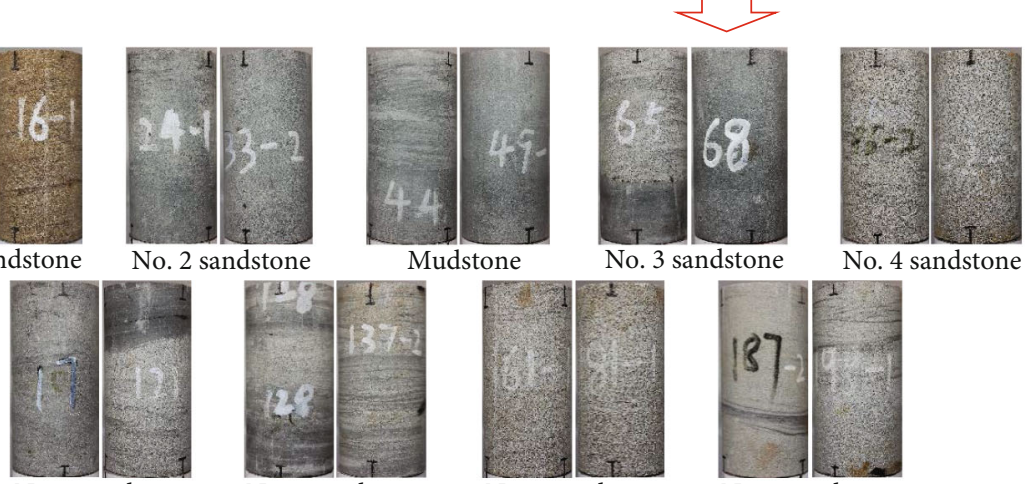

Figure 1: Rock core and standard specimens of all rock layers.

and $\mathrm{S}$ wave differs significantly from that observed for an isotropic background [16]. Experimental investigations also show that the circumferential velocity anisotropy is very obvious in the rocks containing natural fractures and bedding, which has great influence on the detecting results [17]. Hence, ultrasonic wave velocity measurements can be used to determine the anisotropy and the microcrack evolution of rocks during loading [18-21]. Furthermore, the permeability and the porosity of rocks also can be determined based on the connection between mesostructures of rock and ultrasonic wave velocity [22-24]. However, all the predictions by using the wave velocity measurements are statistical equations and have a certain error. In order to improve the prediction accuracy, it is very necessary to systematically investigate the relevance between ultrasonic, mechanical properties, and failure characteristics.

In this paper, we investigate the correlation between dynamic ultrasonic and mechanical properties of sandstones with different buried depths subjected to uniaxial compression tests. It obtained the angles between the failure plane and the directions of minimum/maximum ultrasonic wave velocities. The variations of wave velocities and dynamic elastic properties during the loading process are given, which can provide scientific basis for predicting rock failure and the distribution of mining-induced fissures in overburden.

\section{Material and Testing Equipment}

2.1. Specimens. The rock specimens are obtained from the overburden of No. $2^{-2}$ coal seam of Ningtiaota coalmine in western China. The overlying strata have nine rock layers, including eight sandstone layers and one mudstone layer. The buried depth of rock layers is approximately from $110 \mathrm{~m}$ to $190 \mathrm{~m}$. In the experiments, rock samples are obtained by drilling holes from ground surface, which are processed into standard specimens with the size of $\varphi 50 \times$ $100 \mathrm{~mm}$, as shown in Figure 1. The average buried depth, size, density, and porosity of rock samples are shown in Table 1.

2.2. Testing Equipment. All the tests were conducted using the rock mechanics servo-controlled system RTR-1000 rapid rock triaxial testing system with an axial load capacity of $1000 \mathrm{kN}$, as shown in Figure 2. The test system includes a console, permeameter, load platform, cell pressure intensifier, and pore pressure intensifier. The system can perform triaxial deformation experiments at confining stress up to $140 \mathrm{MPa}$ accurate to $\pm 1 \%$ of applied pressure, axial load up to $1000 \mathrm{kN}$ accurate to $\pm 1 \%$ of reading force, and hydraulic pressure up to $140 \mathrm{MPa}$ accurate to $\pm 1 \%$ of applied pressure. In this experiment, the axial deformation was recorded by a displacement transducer. In addition, the circumferential wave velocity anisotropy is measured by CVA-100 testing system, as shown in Figure 3.

2.3. Testing Procedure. Ultrasound wave velocity test is a very feasible and effective method to evaluate anisotropy property, which does not damage the rock specimens. A pair of piezo-ceramic-based ultrasonic transducers which come in standard constant frequencies of $1 \mathrm{MHz}$ was attached to diametrically opposed sides of the cylindrical specimen, as shown in Figure 3. The pulse-transmission technique is used to estimate the travel time of an ultrasonic stress perturbation within the rock specimen between the 
Table 1: Average buried depth, density, porosity, and size of rock samples.

\begin{tabular}{|c|c|c|c|c|c|c|}
\hline \multirow{2}{*}{ Strata } & \multirow{2}{*}{ Buried depth (m) } & \multirow{2}{*}{ Sample number } & \multicolumn{2}{|c|}{ Size $(\mathrm{mm})$} & \multirow{2}{*}{ Density $\left(\mathrm{g} / \mathrm{cm}^{3}\right)$} & \multirow{2}{*}{ Porosity (\%) } \\
\hline & & & Height & Diameter & & \\
\hline No. 1 sandstone & 113.4 & $3-1 / 16-1$ & $100.10 / 99.92$ & $48.74 / 48.72$ & 2.14 & 20.96 \\
\hline No. 2 sandstone & 123.3 & $24-1 / 33-2$ & $99.77 / 98.54$ & $48.74 / 48.94$ & 2.28 & 23.62 \\
\hline Mudstone & 136.0 & $44 / 49-2$ & $98.36 / 100.10$ & $48.93 / 48.93$ & 2.39 & 14.84 \\
\hline No. 3 sandstone & 145.9 & $65 / 68$ & $99.83 / 92.88$ & $49.03 / 48.90$ & 2.35 & 20.46 \\
\hline No. 4 sandstone & 154.1 & $86-2 / 102-2$ & $100.20 / 99.14$ & $48.76 / 48.97$ & 2.24 & 23.01 \\
\hline No. 5 sandstone & 162.6 & $107 / 121$ & $100.10 / 99.88$ & $48.84 / 48.93$ & 2.39 & 12.18 \\
\hline No. 6 sandstone & 170.8 & $128 / 137-2$ & $99.15 / 100.20$ & $48.77 / 49.14$ & 2.41 & 9.44 \\
\hline No. 7 sandstone & 183.6 & $161-1 / 181-1$ & $100.10 / 100.00$ & $48.92 / 48.83$ & 2.16 & 19.93 \\
\hline No. 8 sandstone & 191.8 & $187-2 / 198-1$ & $100.00 / 99.19$ & $48.95 / 49.07$ & 2.36 & 13.45 \\
\hline
\end{tabular}

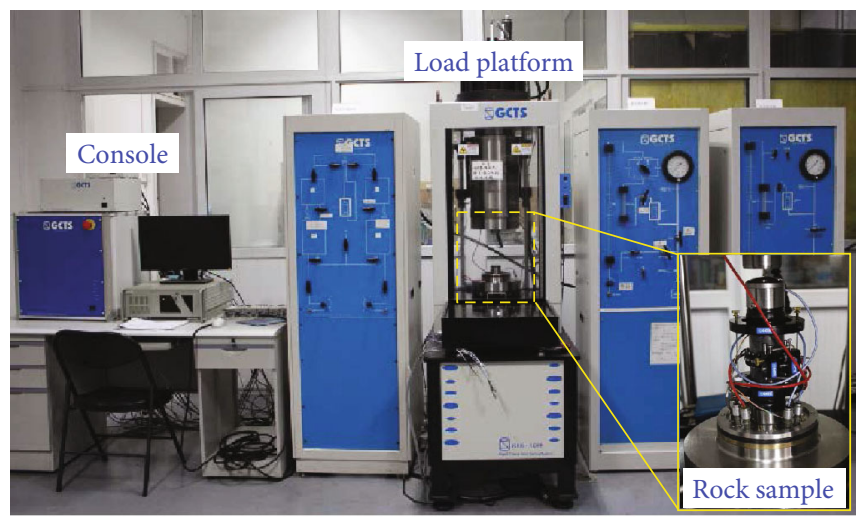

FiguRE 2: Rapid triaxial rock resting system (RTR-1000).

source and the receiver. Knowing the travel distance allows us to calculate the corresponding ultrasonic wave velocity. Before the mechanical test, the circumferential $\mathrm{P}$ wave velocity anisotropy of all specimens was measured internally at every $10^{\circ}$. For each angle, the radial $\mathrm{P}$ wave velocity was measured three times within a horizontal plane located at the sample's midheight.

Additionally, uniaxial compression test is applied to obtain mechanical properties of all the rock layers at room temperature. The installation drawing of rock specimens and sensors is shown in Figure 3. The loading is controlled by the displacement loading control mode, and the loading rate is fixed at $0.02 \mathrm{~mm} / \mathrm{min}$. The loading upper limit is fixed at $5 \%$ axial strain to avoid the damage of transducers. Both velocities of $\mathrm{P}$ and $\mathrm{S}$ waves are measured every 30 seconds.

\section{Analysis of Mechanical Experiments Results}

3.1. Stress-Strain Curves and Mechanical Parameters. Figure 4 shows the complete stress-strain curves of all the rock specimens under uniaxial compression test, in which $\varepsilon_{a}, \varepsilon_{r}$, and $\varepsilon_{v}$ are defined as the axial strain, radial strain, and volumetric strain during the loading process. It is obvious that the uniaxial compressive strengths of two rock samples in most rock layers have no big differences except the No. 3 sandstone, which indicates the rock layers are less affected by geological actions. The peak axial

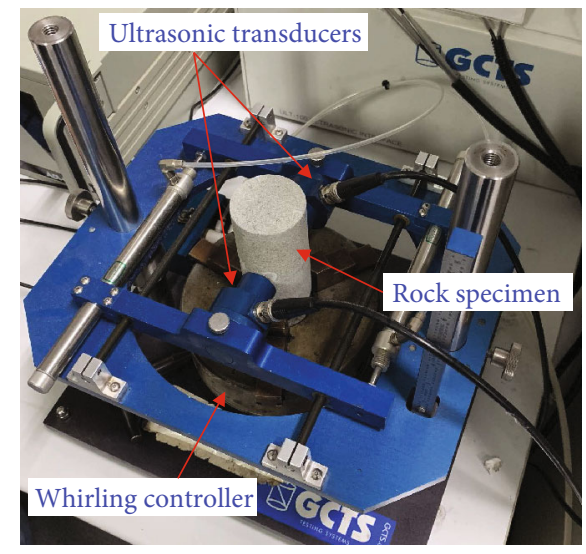

FIgURe 3: CVA-100 wave velocity anisotropy testing system.

strains of all the rock layers are mainly in the interval of $0.5 \% \sim 1.0 \%$. Generally, the stress-strain curve has four phases: crack closure phase, elastic phase, crack growth stage, and postpeak stage. In the first phase, the stressstrain curve is nonlinear due to the closure of the microcracks, which is influenced by the initial porosity. The crack closure phase is the most obvious in the No. 2 sandstone layer due to the maximum porosity of overlying strata. Additionally, the Young's modulus $E$ and uniaxial compressive strength $\sigma_{c}$ can be obtained based on the 

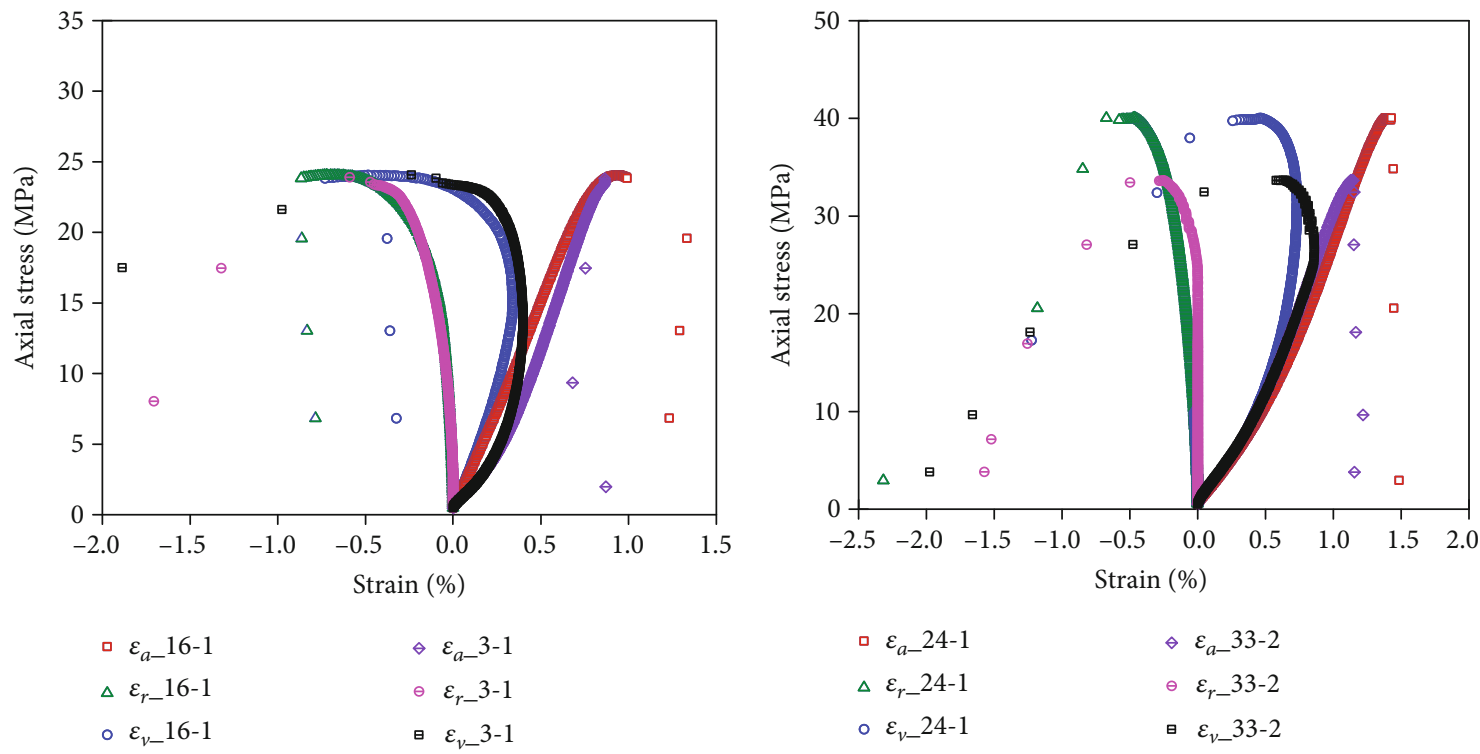

$\begin{array}{ll}\text { ㄷ } & \varepsilon_{a-} 24-1 \\ \Delta & \varepsilon_{r-2} 24-1 \\ \circ & \varepsilon_{v \_} 24-1\end{array}$

$\diamond \varepsilon_{a-} 33-2$

- $\varepsilon_{r-} 33-2$

(a) No. 1 sandstone

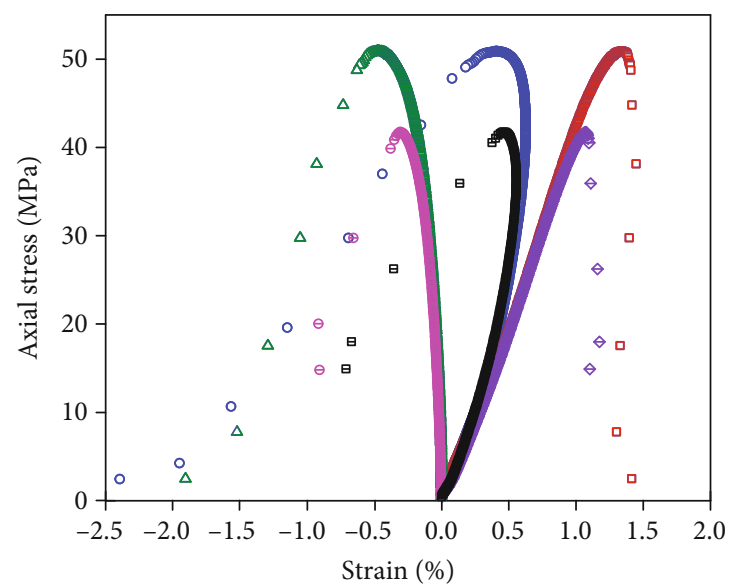

(b) No. 2 sandstone

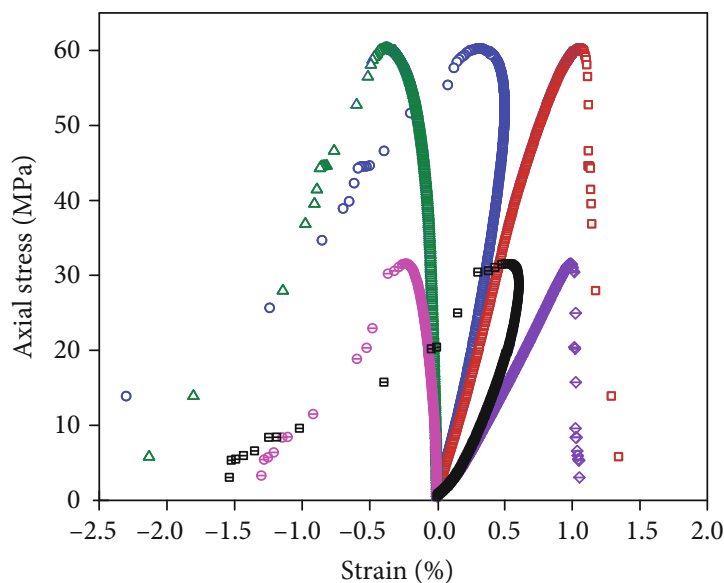

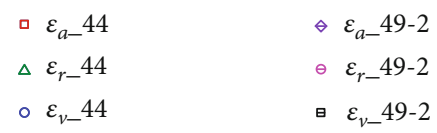

(c) Mudstone

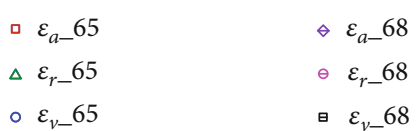

(d) No. 3 sandstone

Figure 4: Continued. 

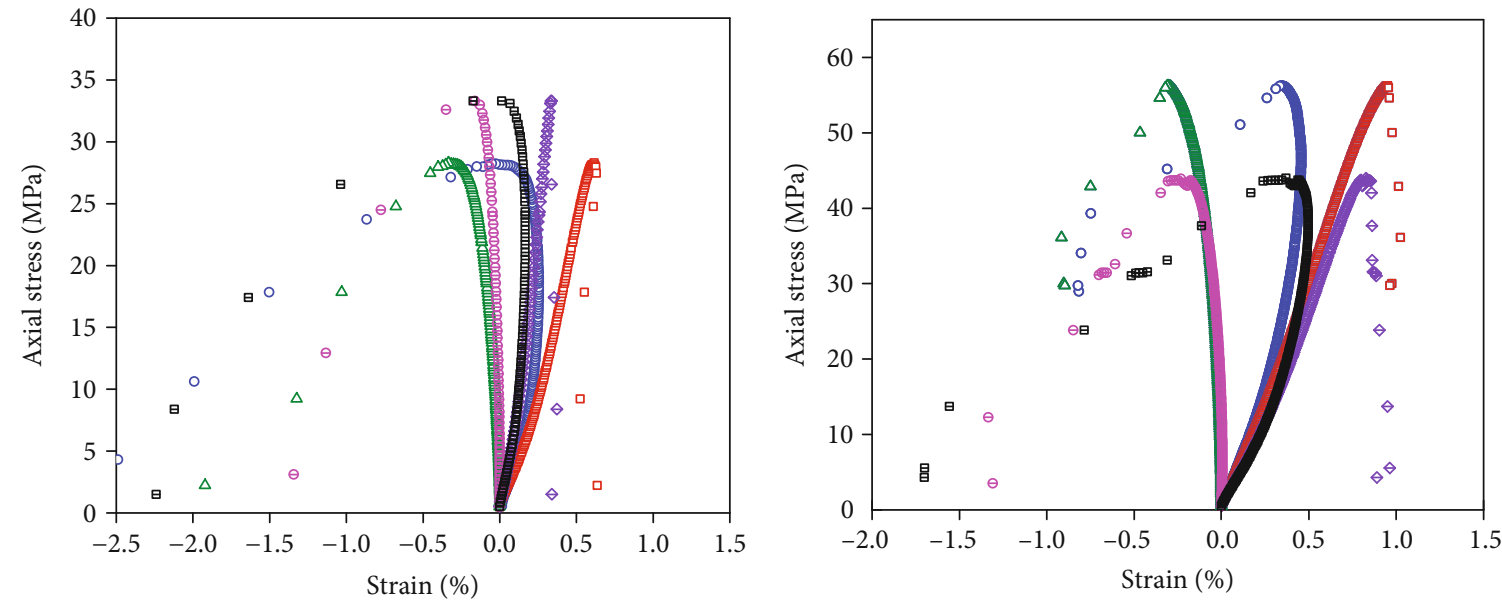

$$
\begin{array}{ll}
\square \varepsilon_{\mathrm{a}-} 86-2 & \ominus \varepsilon_{\mathrm{a}-102-2} \\
\Delta \varepsilon_{\mathrm{r}-86-2} & \ominus \varepsilon_{\mathrm{r}-102-2} \\
\circ \varepsilon_{\mathrm{v}-86-2} & \quad \forall \varepsilon_{\mathrm{v}-102-2}
\end{array}
$$

$$
\begin{array}{ll}
\square \varepsilon_{a \_} 107 & \ominus \varepsilon_{a-} 121 \\
\Delta \varepsilon_{r \_} 107 & \ominus \varepsilon_{r \_} 121 \\
\circ \varepsilon_{v \_} 107 & \quad \forall \varepsilon_{v \_} 121
\end{array}
$$

(e) No. 4 sandstone
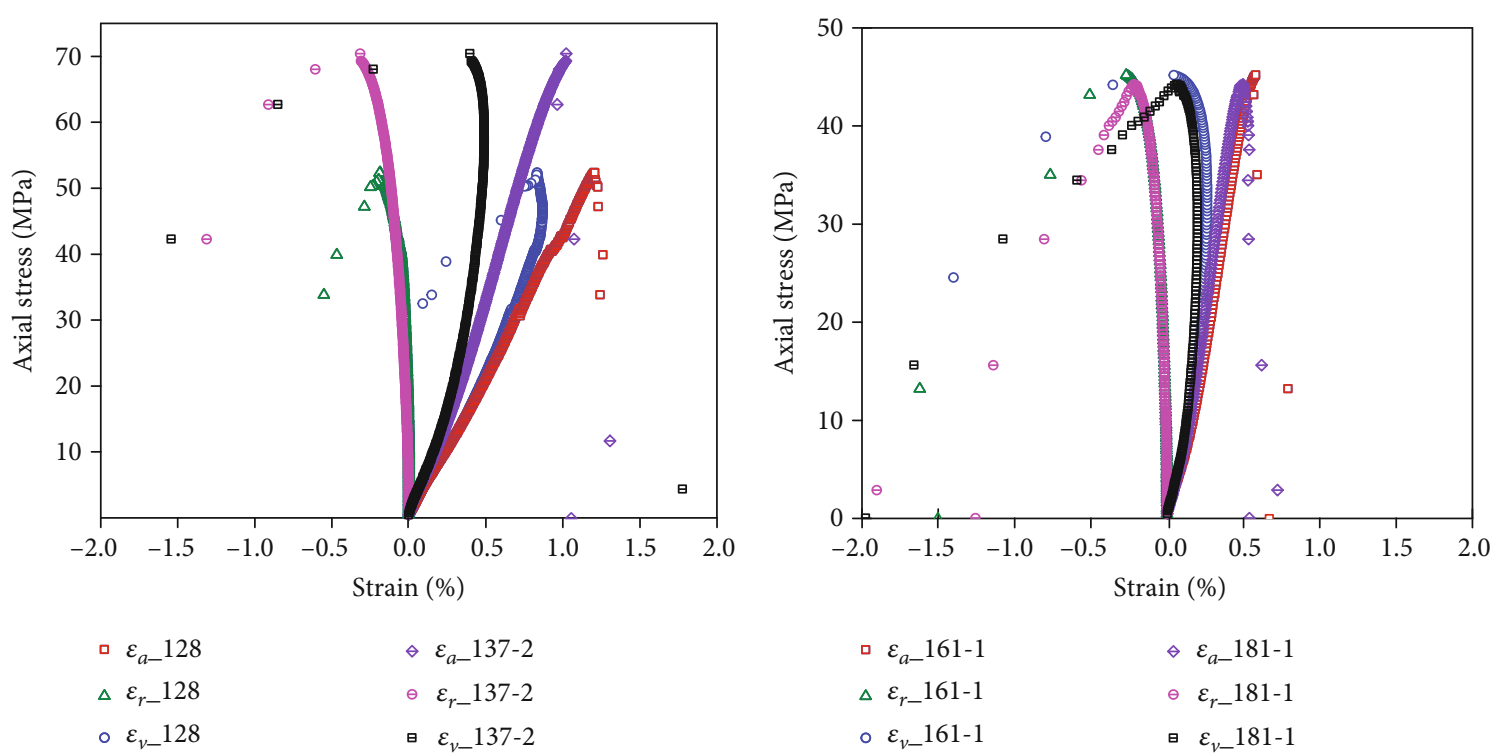

(g) No. 6 sandstone

(h) No. 7 sandstone

Figure 4: Continued. 


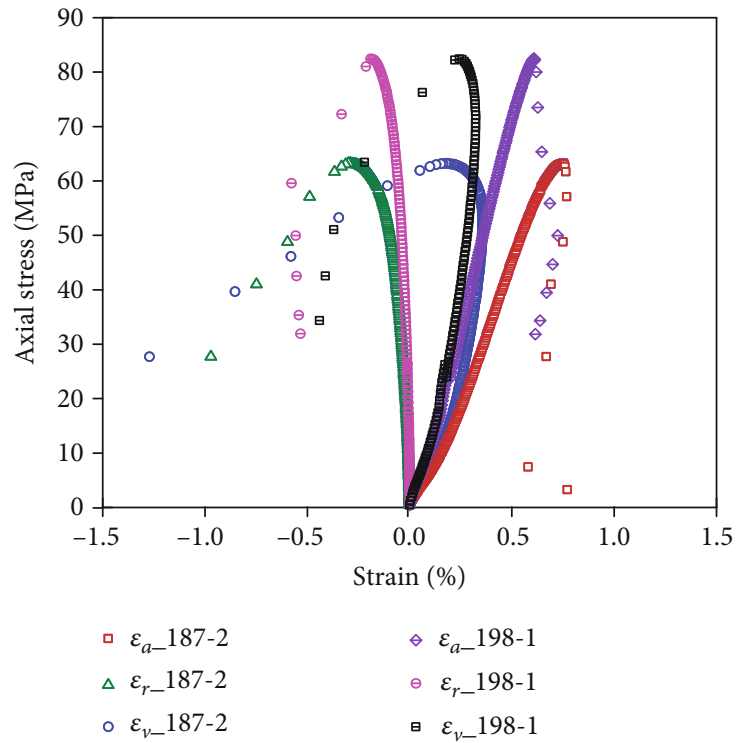

(i) No. 8 sandstone

FIGURE 4: Complete stress-strain curves of all the specimens.

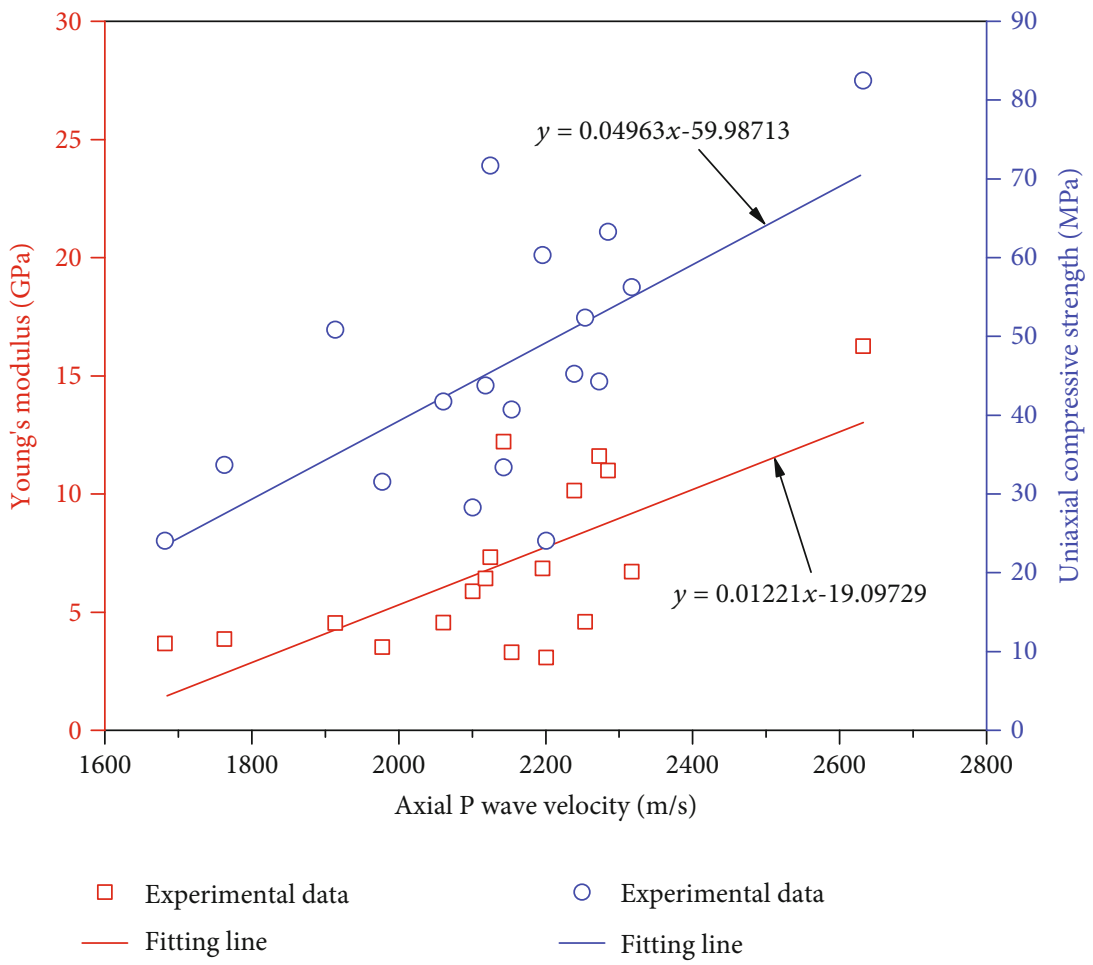

FIGURE 5: Correlation of uniaxial compressive strength, Young's modulus, and axial P wave velocity.

stress-strain curves. Figure 5 shows the relevance between the two mechanical properties and the axial $\mathrm{P}$ wave velocity. It is obvious that the Young's modulus and uniaxial compressive strength are positively correlated with the axial $\mathrm{P}$ wave velocity.

3.2. Circumferential Velocity Anisotropy and Failure Direction. Based on the travel time of an ultrasonic wave between the source and the receiver and the diameter of rock specimen, the circumferential wave velocity anisotropy of all specimens was obtained and the mean value for each direction is shown in Figure 4. The blue line represents the maximum wave velocity direction, and the red line represents the minimum wave velocity direction. It is obvious that the radial $\mathrm{P}$ wave velocity fluctuates greatly in different rock layers. The minimum and maximum radial 


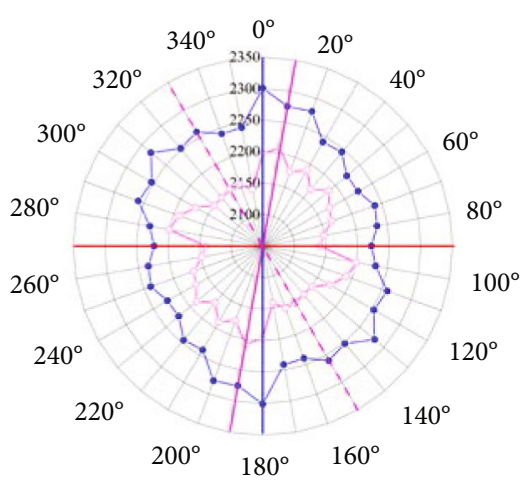

_ Minimum wave direction

- Maximum wave direction

--- Failure direction

(a) No. 1 sandstone

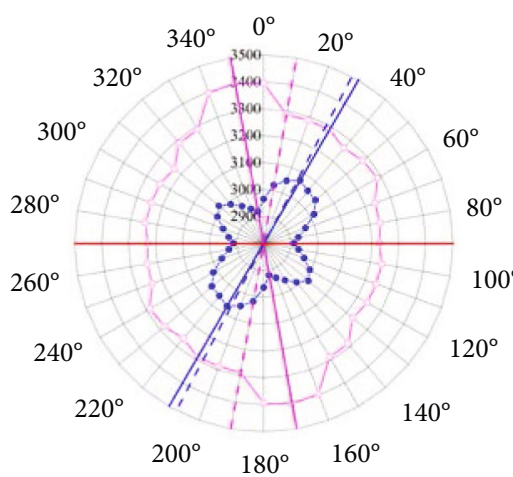

_ Minimum wave direction

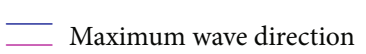

--- Failure direction

(d) No. 3 sandstone

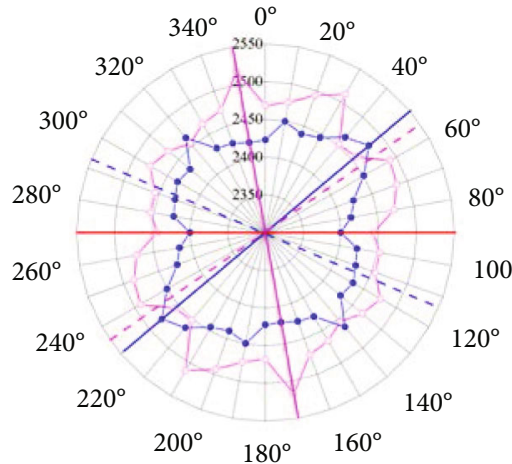

_ Minimum wave direction

— Maximum wave direction

--- Failure direction

(b) No. 2 sandstone
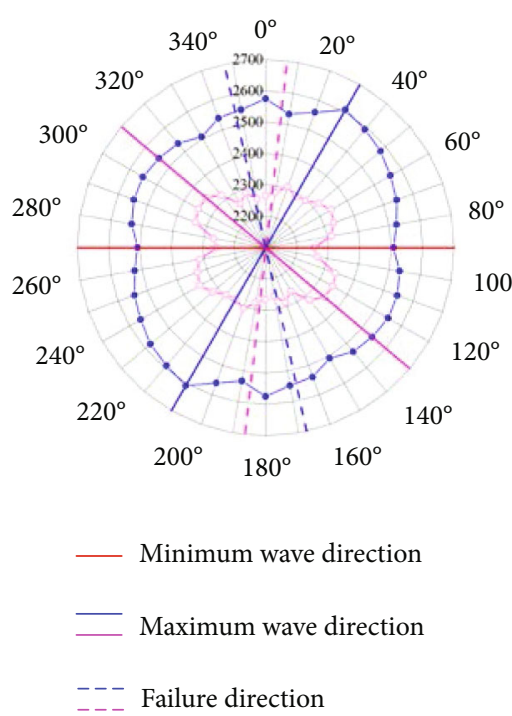

(e) No. 4 sandstone

FIgure 6: Continued.

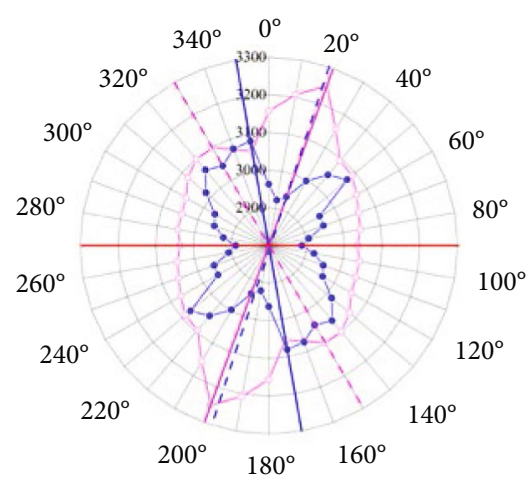

_ Minimum wave direction

— Maximum wave direction

--- Failure direction

(c) Mudstone

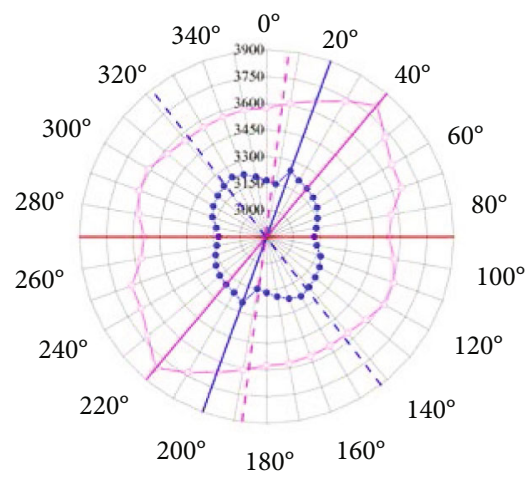

_ Minimum wave direction

— Maximum wave direction

--- Failure direction

(f) No. 5 sandstone 

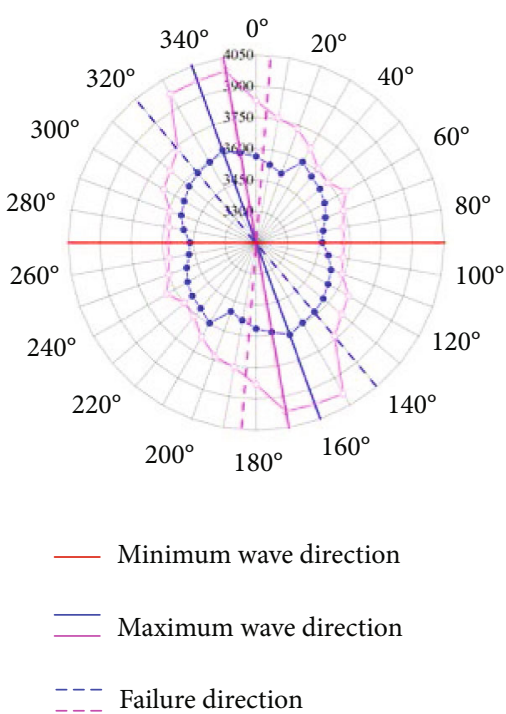

(g) No. 6 sandstone
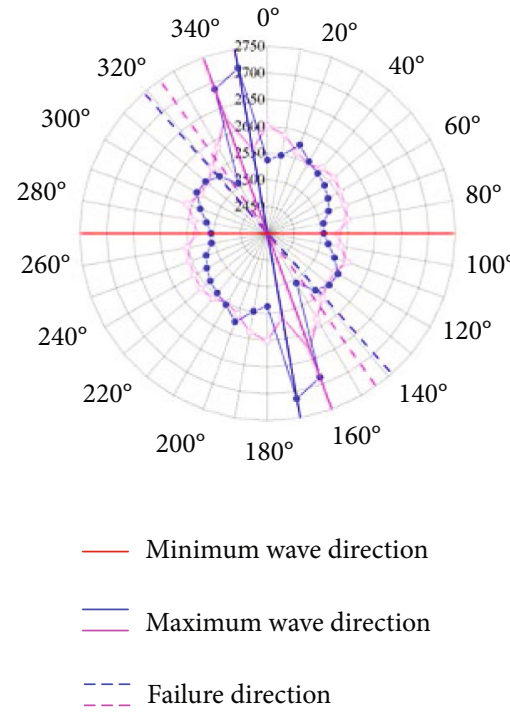

(h) No. 7 sandstone
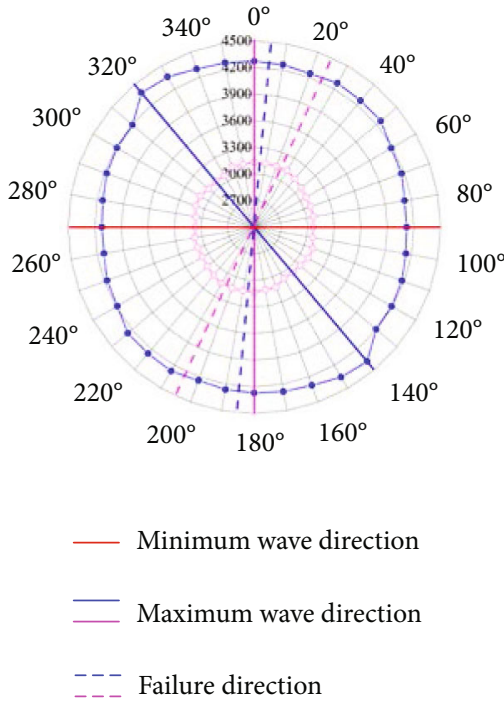

(i) No. 8 sandstone

Figure 6: $\mathrm{P}$ wave velocities of sandstone, in which the blue line represents the maximum wave velocity direction and the red line represents the minimum wave velocity direction.

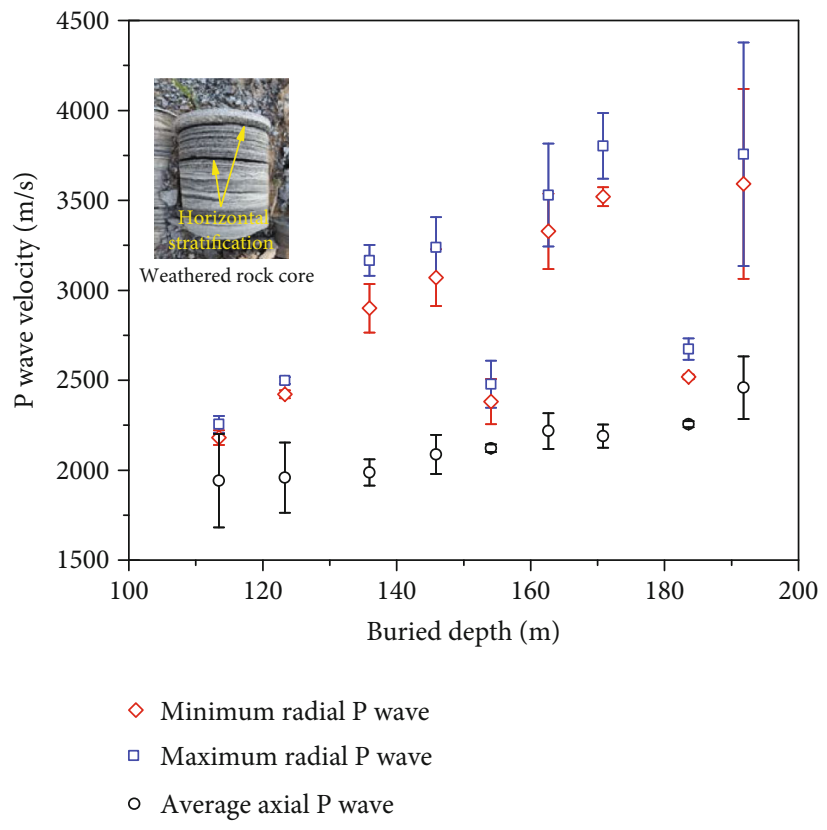

Figure 7: Variation of P wave velocity with an increase of buried depth.

$\mathrm{P}$ wave velocity in the sandstone samples are approximately $2100 \mathrm{~m} / \mathrm{s}$ and $4000 \mathrm{~m} / \mathrm{s}$, respectively. The differences of radial $\mathrm{P}$ wave velocities are great in No. 3 sandstone (Figure 6(d)), No. 4 sandstone (Figure 6(e)), No. 5 sandstone (Figure 6(f)), and No. 8 sandstone (Figure 6(i)). The difference of the radial $\mathrm{P}$ wave velocities in No. 3 sandstone, No. 4 sandstone, No. 5 sandstone, and No. 8 sandstone is about $300 \mathrm{~m} / \mathrm{s}, 250 \mathrm{~m} / \mathrm{s}, 550 \mathrm{~m} / \mathrm{s}$, and $1200 \mathrm{~m} / \mathrm{s}$, respectively. The circumferential velocity anisotropy is most pronounced in the mudstone (Figure 6(c)),
No. 3 sandstone (Figure 6(d)), No. 5 sandstone (Figure 6(f)), No. 6 sandstone (Figure 6(g)), and No. 7 sandstone (Figure 6(h)).

The circumferential velocity anisotropy of rock specimens may be caused by the difference of initial horizontal stress. Cracks will open after the unloading of the initial stress due to core drilling. $\mathrm{P}$ wave velocity generally attenuates greater in the maximum stress direction and attenuates less in the minimum stress direction. Horizontal stratifications are the main structure in the sedimentary 


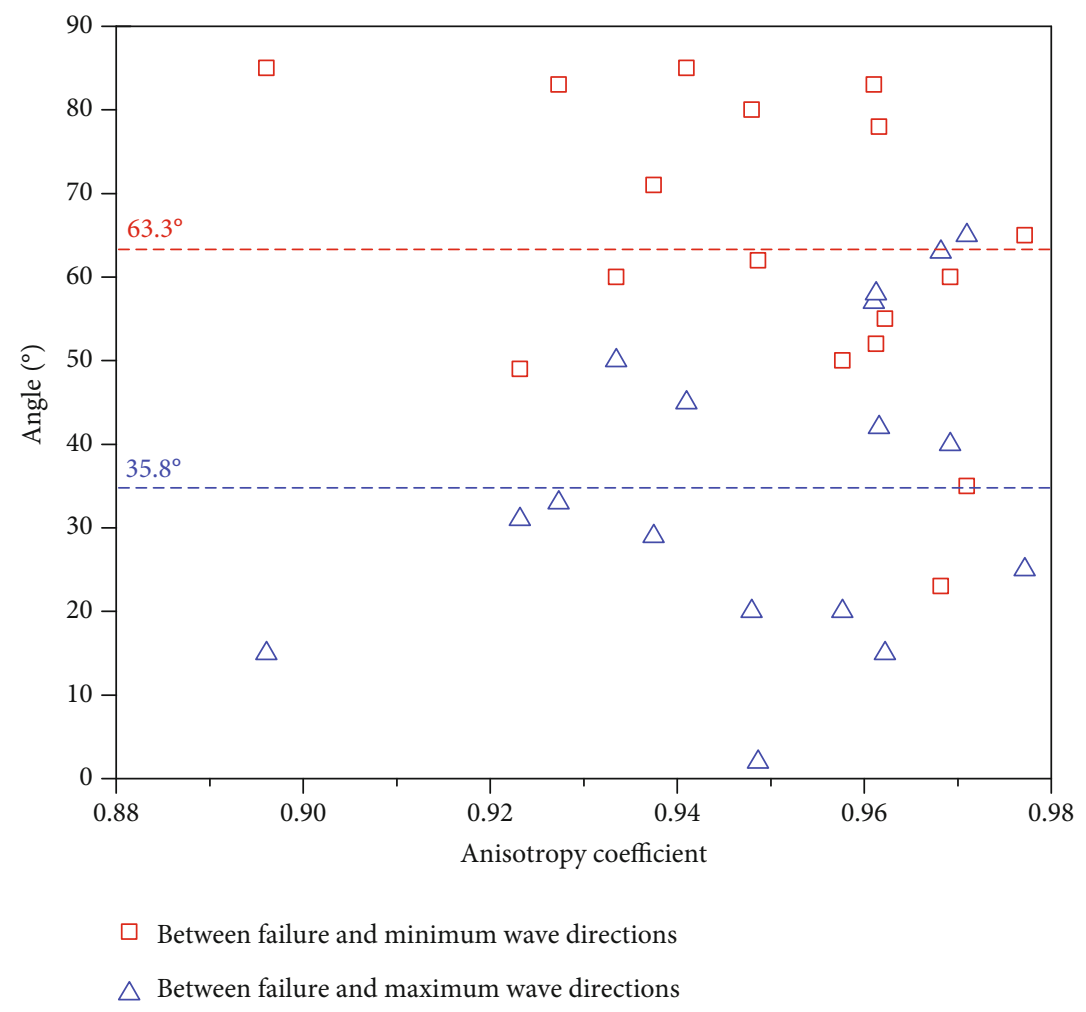

Figure 8: Angles between the failure plane and the minimum and maximum wave directions in different rock layers.

rock, which can be clearly seen after weathering, as shown in Figure 7. Due to the effect of horizontal stratifications, the average axial $\mathrm{P}$ wave velocity is obviously greater than the radial wave velocity. Overall, the axial and radial $\mathrm{P}$ wave velocities increase with an increase of buried depth, except that the radial wave velocity of No. 4 sandstone and No. 7 sandstone suddenly drops. The main reason may be that the content of quartz is the smallest in the No. 4 sandstone and No. 7 sandstone based on the Xray diffraction test of the mineral composition. Additionally, we define the ratio of minimum wave velocity and maximum wave velocity as the anisotropy coefficient. As the anisotropy coefficient increases, the circumferential velocity anisotropy is no obvious and the direction of failure plane becomes more random, as shown in Figure 8 . The average angles between the failure plane and the minimum or maximum wave directions are approximately $63.3^{\circ}$ and $35.8^{\circ}$, respectively. When the anisotropy coefficient is small, the angles between the failure plane and the minimum or maximum wave directions tend to become $90^{\circ}$ and $0^{\circ}$, respectively.

3.3. Variation of Ultrasonic Characteristics during Loading. The variations of axial compressive stress, axial $\mathrm{P}$ wave, and $\mathrm{S}$ wave velocity during the loading process are shown in Figure 9. Most stress-strain curves have the typical characteristics of five phases, namely, crack closure phase, elastic phase, crack stable growth phase, crack unstable growth phase, and postpeak stage [6-8]. The $\mathrm{P}$ wave velocity increases faster than the $S$ wave velocity during loading. In the first phase, the stress-strain curves tend to display an initial nonlinear phase due to the closure of the microcracks. The axial $\mathrm{P}$ wave and $\mathrm{S}$ wave velocities rapidly increase in most rock specimens during the initial compression stage. However, the $\mathrm{P}$ wave and $\mathrm{S}$ wave velocities fluctuate greatly in the rock specimens of No. 1 sandstone, No. 2 sandstone, No. 3 sandstone, and No. 4 sandstone, which results in the unstable increasing rates of axial $\mathrm{P}$ wave and $\mathrm{S}$ wave velocities, as shown in Figure 10. The large wave velocity fluctuation may be caused by a large porosity and obvious anisotropy existing in the No. 1, No. 2, No. 3, and No. 4 sandstone layers, as shown in Table 1. Furthermore, the crack closure due to the initial loading phase is not average. Both porosity and crack closure speed differences result in great fluctuation of axial $\mathrm{P}$ wave and $\mathrm{S}$ wave velocities. When the compressive stress reaches $40 \% \sim 60 \%$ of the peak stress, namely, elastic phase, the increasing rates of wave velocities become stable due to elastic deformations of the rock specimens. In the crack stable growth phase, the axial $\mathrm{P}$ wave and $S$ wave velocities in most rock specimens increase slowly due to initial propagation of the new microcracks and flaws. Then, the new microcracks will rapidly increase and expand, and the stress-strain curve displayed the crack unstable growth phase. The axial $S$ wave velocity has a slow decreasing phase before the peak stress, which is a critical signal to predict the rock failure. The slow decreasing of axial $S$ wave velocity before the 


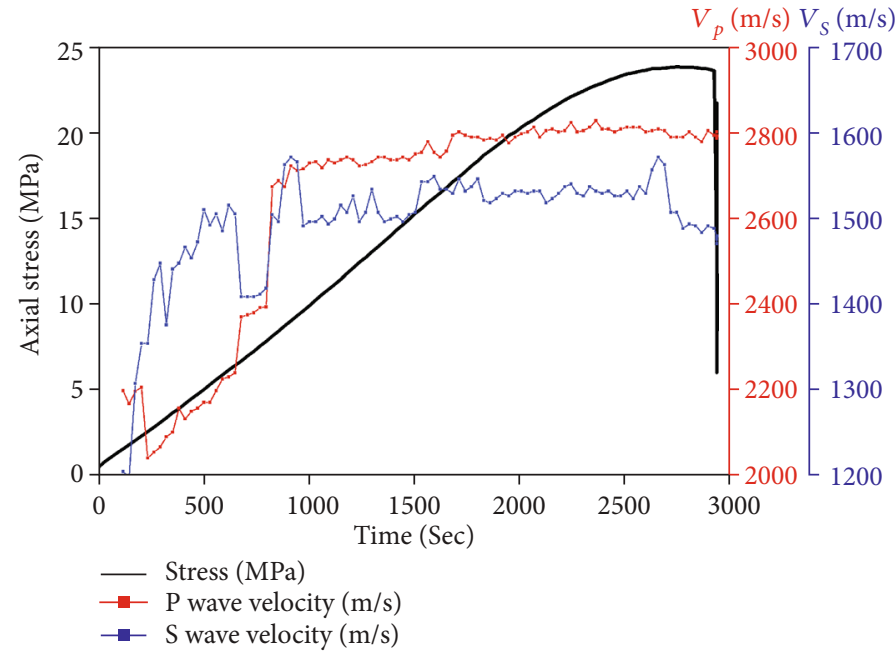

(a) No. 1 sandstone

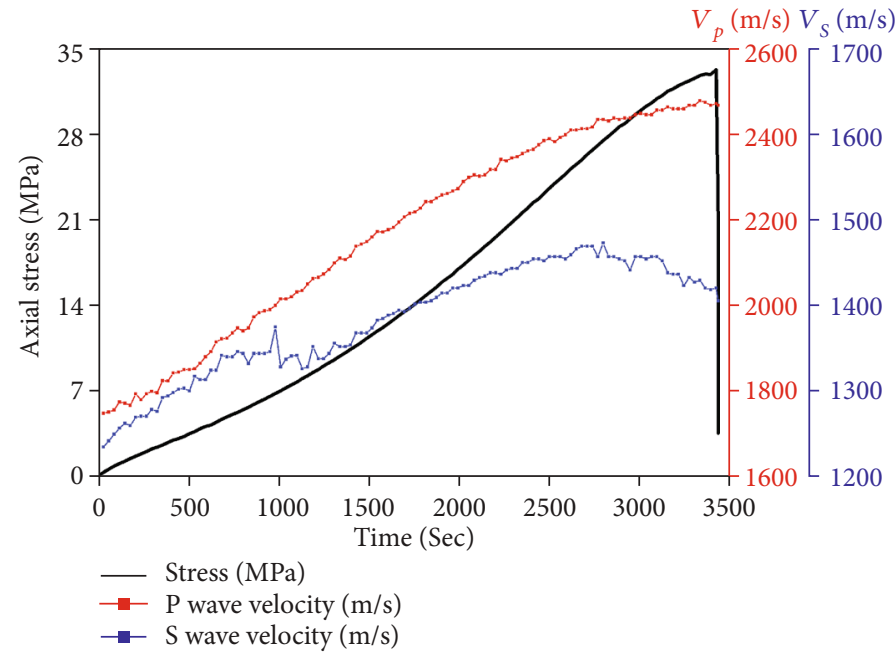

(b) No. 2 sandstone

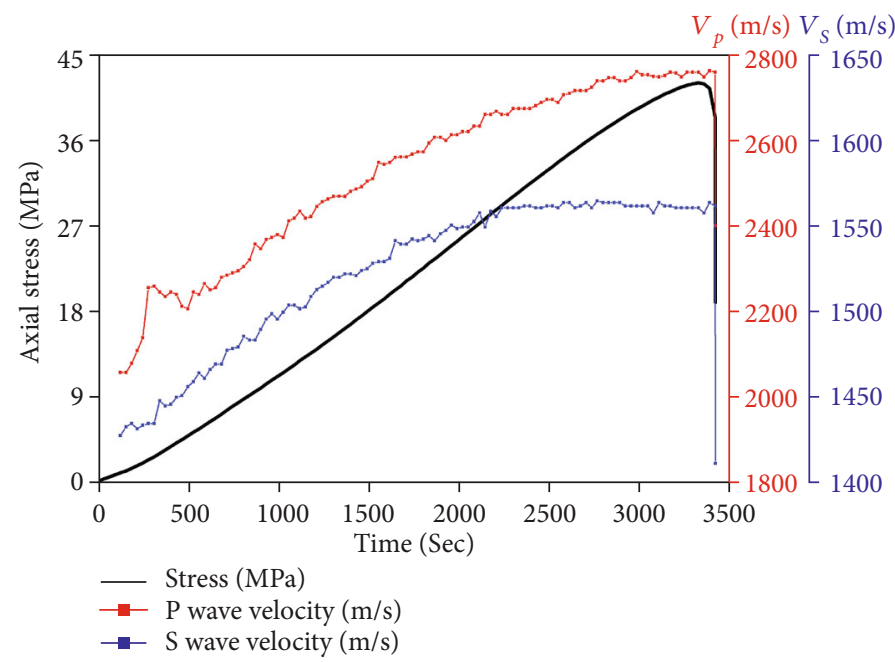

(c) Mudstone

Figure 9: Continued. 


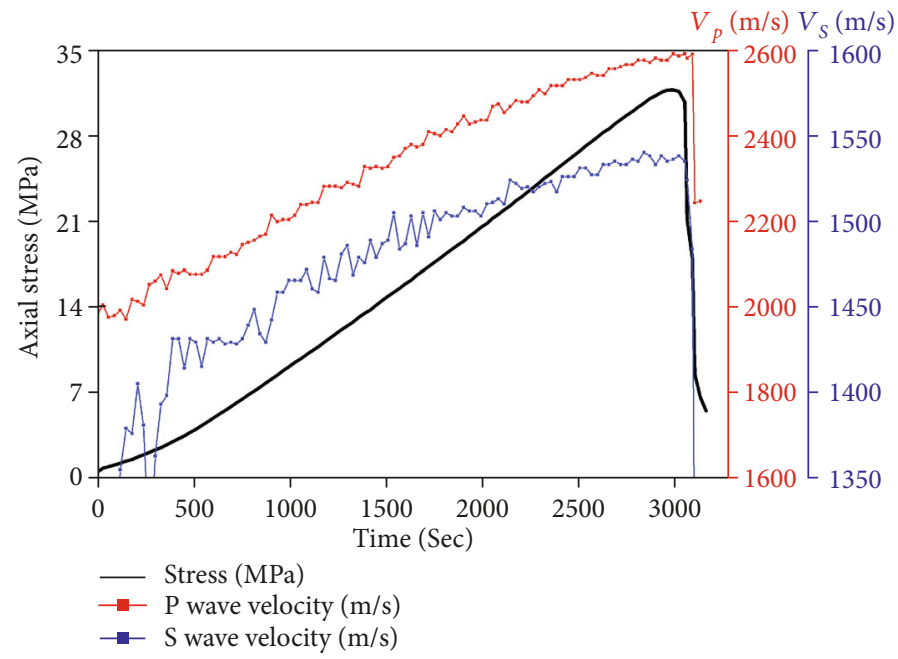

(d) No. 3 sandstone

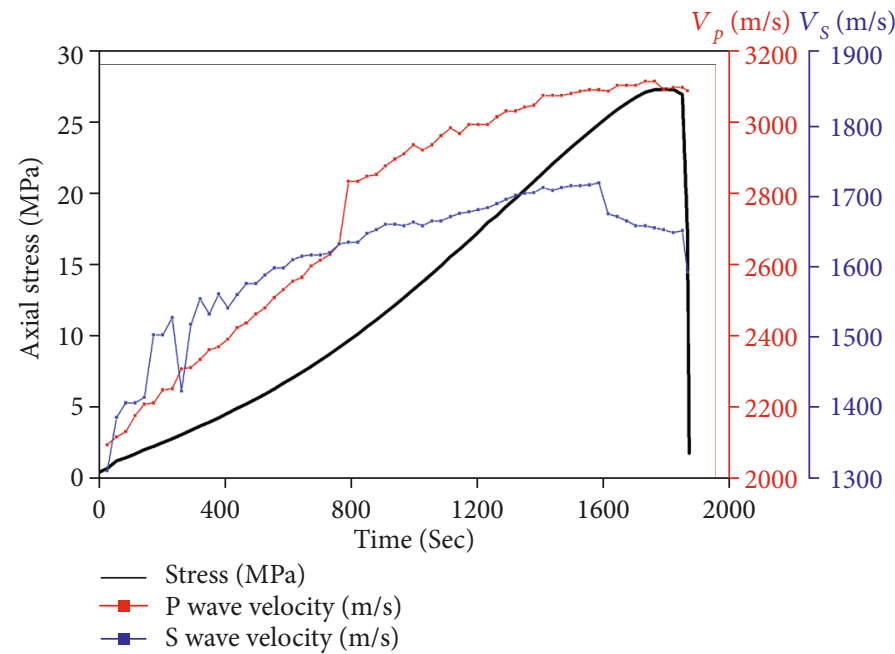

(e) No. 4 sandstone

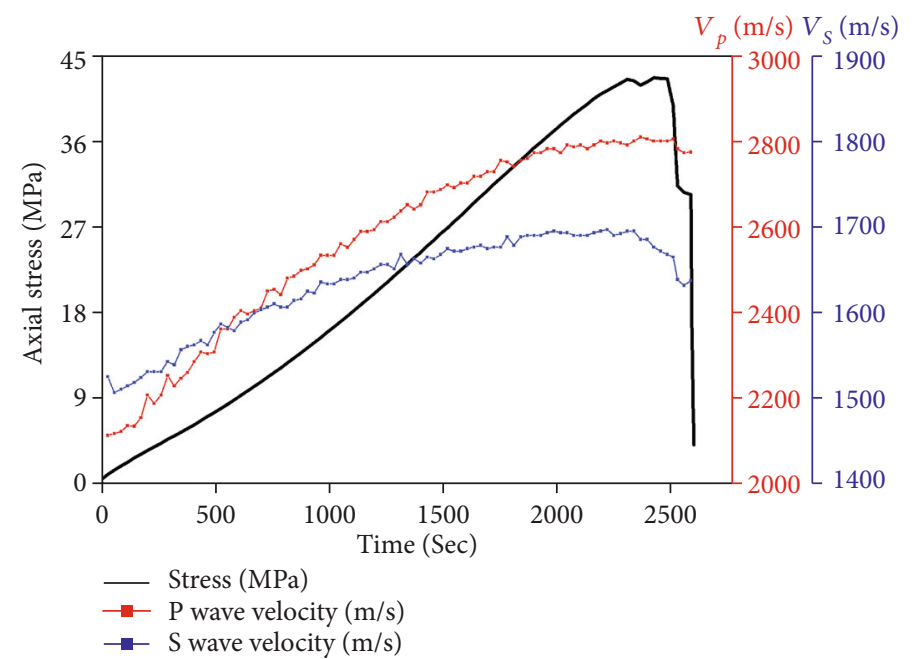

(f) No. 5 sandstone

Figure 9: Continued. 


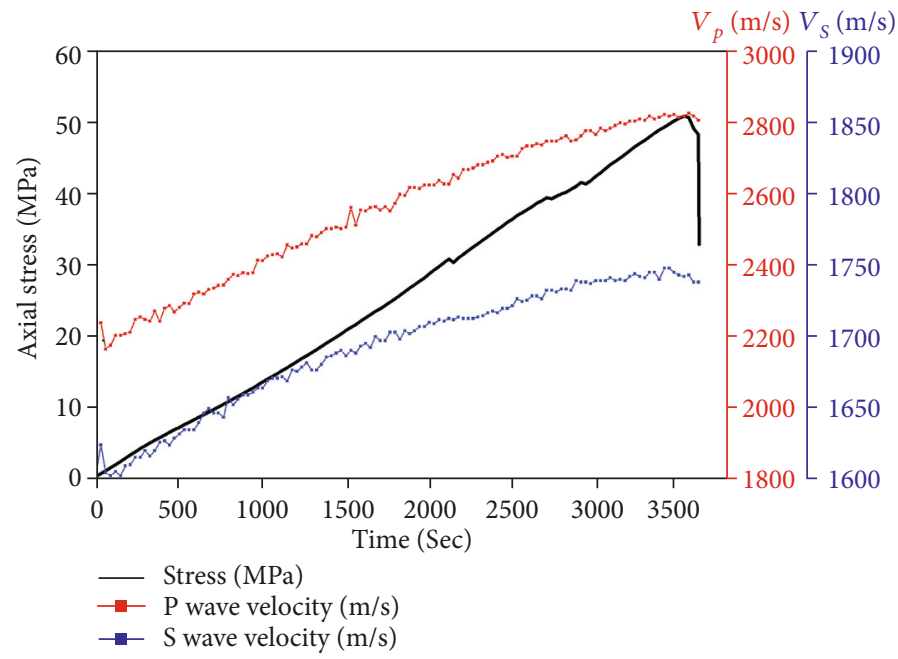

(g) No. 6 sandstone

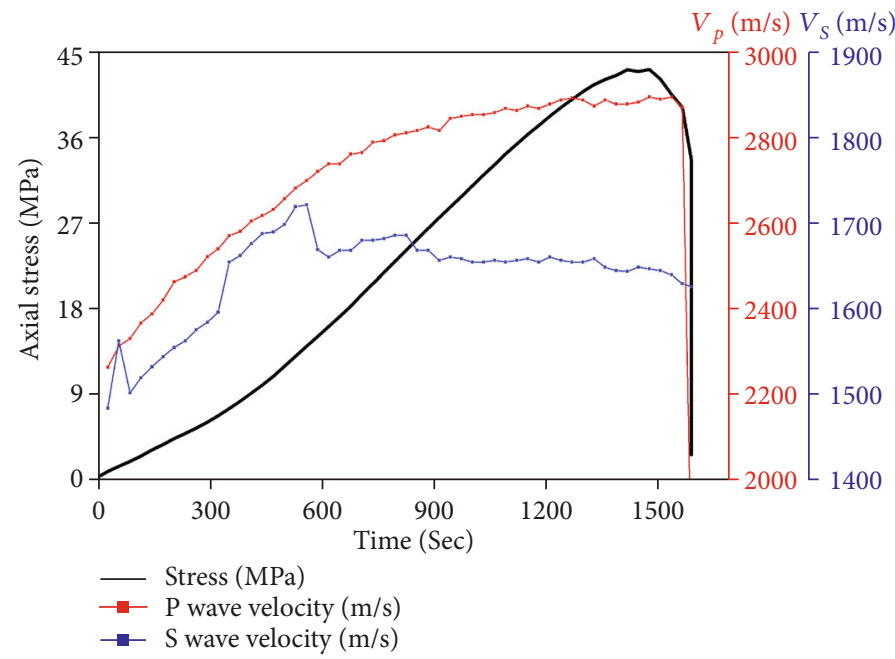

(h) No. 7 sandstone

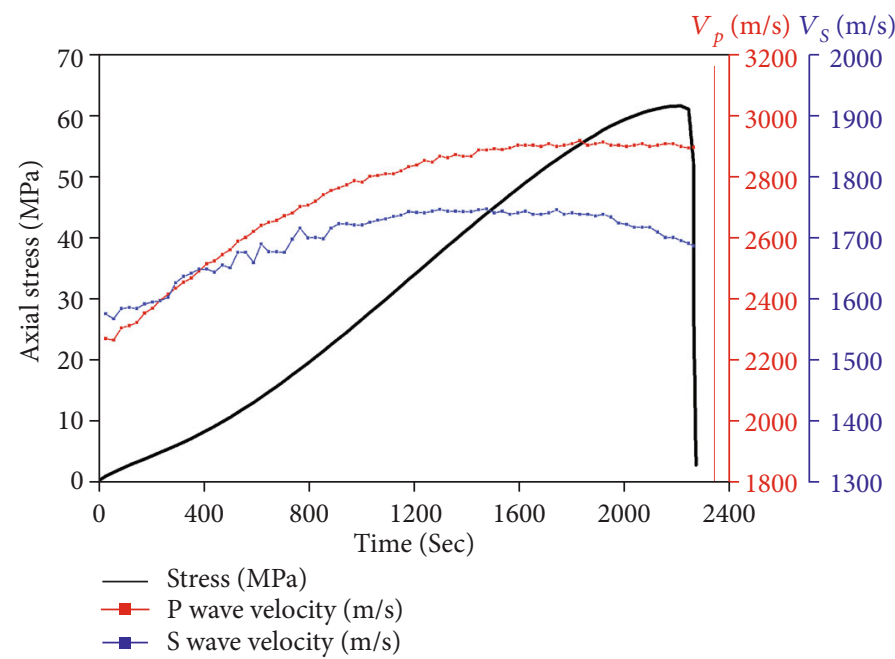

(i) No. 8 sandstone

FIGURE 9: Variations of axial wave velocity and compressive stress during the loading process. 


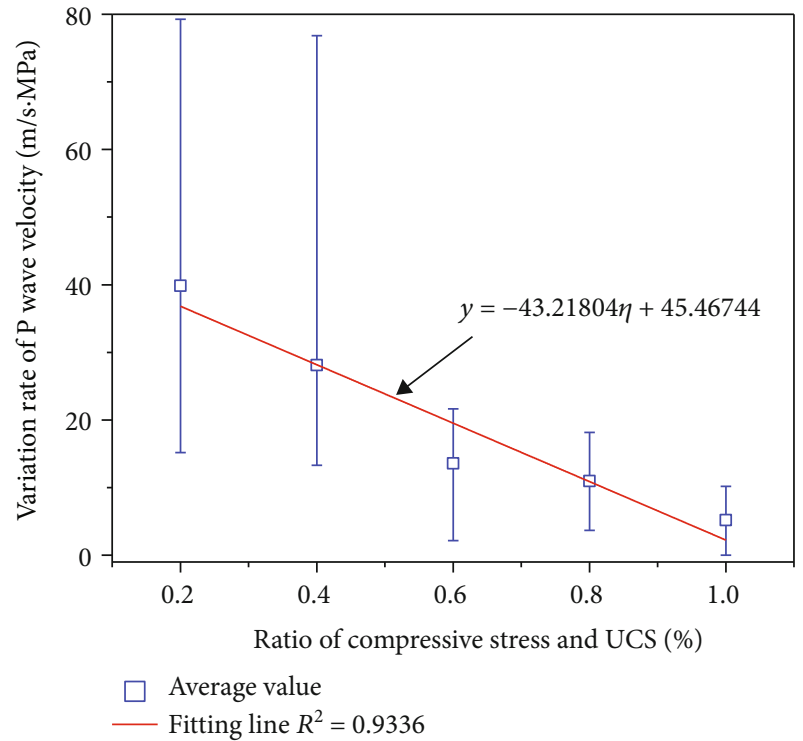

(a)

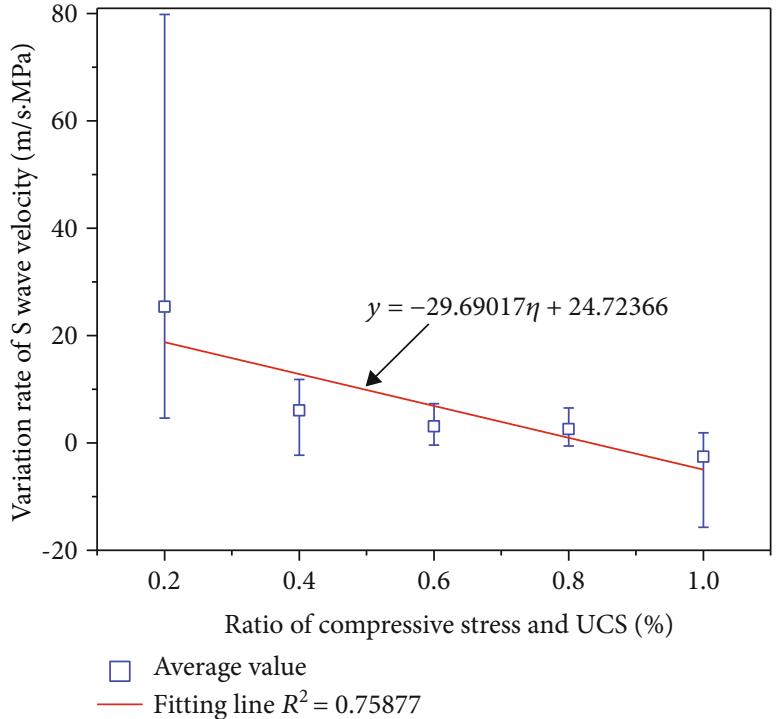

(b)

FIgURE 10: Variation rate of $\mathrm{P}$ wave and $\mathrm{S}$ wave velocities during the loading process.

peak stress may be caused by the occurrence of split microcracks. In the postpeak stage, both the axial $\mathrm{P}$ wave and $S$ wave velocities will suddenly drop to $0 \mathrm{~m} / \mathrm{s}$ due to the occurrence of the macrocracks, which prevent the wave propagation.

Figure 11 shows the failure patterns of rock specimens, in which the yellow line represents splitting failure plane and the red line represents shear failure plane. It is obvious that most of the rock specimens are damaged due to splitting failure combined with shear failure, and the dip angle of failure plane is between $60^{\circ}$ and $90^{\circ}$. The shear failure plane mainly occurs in the middle of the rock specimens, and most splitting failure appears near the upper and lower sections. The main reason is that the damage of rock specimen under uniaxial compression is caused by the inside shear failure [25]. However, there is no obvious shear failure plane in the No. 121 sample of the No. 5 sandstone (Figure 11(f)), the No. 128 sample of the No. 6 sandstone (Figure 11(g)), and the No. 181-1 sample of the No. 7 sandstone (Figure 11(h)). Two intersecting shear planes with an included angle of approximately $50^{\circ}$ occur in the No. 161-1 sample of the No. 7 sandstone (Figure 11(h)) and the No. 187-2 sample of the No. 8 sandstone (Figure 11(i)). Two parallel shear planes appear in the No. 107 sample of the No. 5 sandstone (Figure 11(f)), and only one shear plane in other failure samples. The experiment results show that the failure patterns of most rock samples have no large difference, which indicates that the rock layers are homogeneous.

\section{Discussion}

The ultrasonic wave velocity can be used to calculate the dynamic elastic properties, such as dynamic Young's mod- ulus and dynamic Poisson's ratio, which is very convenient on site to assess the stability of rock mass. The calculation equations of the dynamic Poisson's ratio and dynamic Young's modulus are as follows $[18,26]$ :

$$
\begin{aligned}
\mu_{d} & =\frac{V_{p}^{2}-2 V_{s}^{2}}{2\left(V_{p}^{2}-V_{s}^{2}\right)}, \\
E_{d} & =\frac{\rho\left(1+\mu_{d}\right)\left(1-2 \mu_{d}\right) V_{p}^{2}}{1-\mu_{d}},
\end{aligned}
$$

where $\mu_{d}$ is the dynamic Poisson ratio, $E_{d}$ is the dynamic Young's modulus, $V_{p}$ is the $\mathrm{P}$ wave velocity, $V_{s}$ is the $\mathrm{S}$ wave velocity, and $\rho$ is the density of rock.

Substituting the dynamic wave velocities into the Eq. (1) and Eq. (2), the dynamic elastic properties of the sandstones subjected to uniaxial compression can be obtained, as shown in Figure 12. Both the dynamic Young's modulus and the dynamic Poisson's ratio nonlinearly increase first, but the increasing rate gradually decreases. Finally, the elastic properties almost keep constant. Additionally, the dynamic Poisson's ratio is negative during the initial compression stage in the mudstone (Figure 12(c)), No. 5 sandstone (Figure 12(f)), and No. 6 sandstone (Figure $12(\mathrm{~g}))$. This phenomenon is very scarce in the traditional deformation of brittle materials, because majority of rocks commonly display a positive Poisson's ratio between 0 and 0.5. However, some investigations presented the occurrence of negative Poisson's ratio of rocks under uniaxial compressive test. Granites that experience high-temperature treatment can exhibit negative Poisson's ratio under low compressive stresses [27]. Zaitsev et al. 


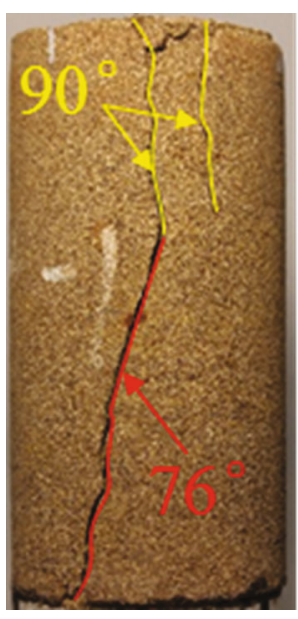

(a) No. 1 sandstone

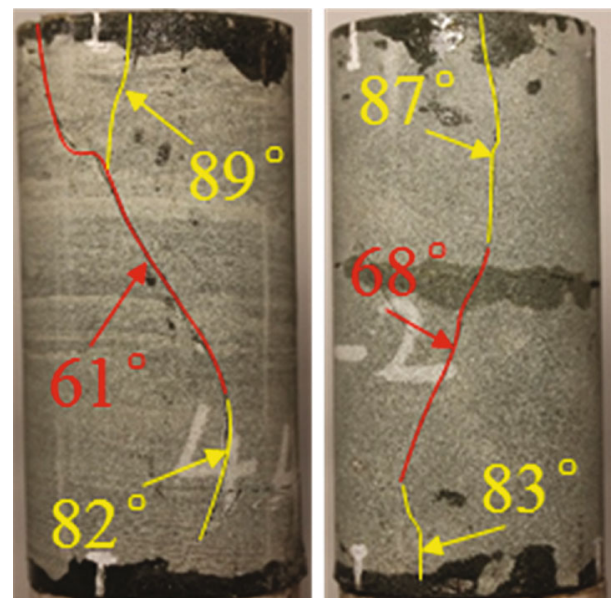

(c) Mudstone
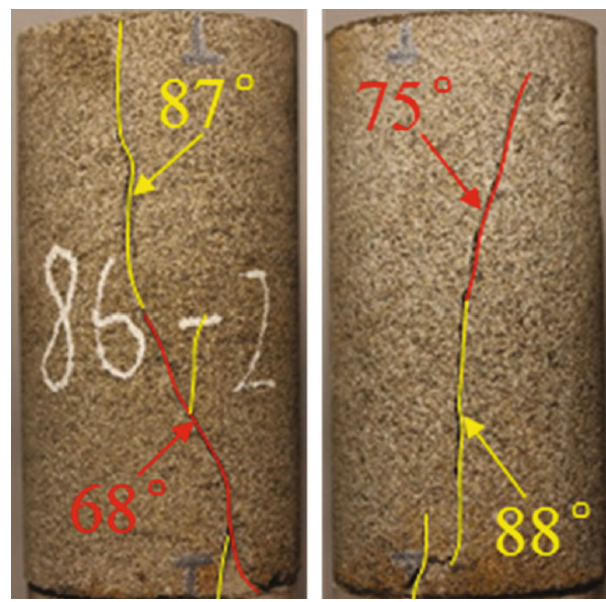

(e) No. 4 sandstone

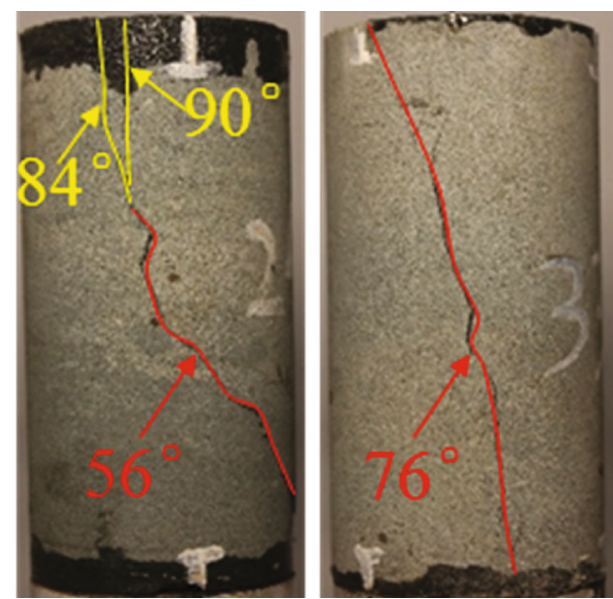

(b) No. 2 sandstone

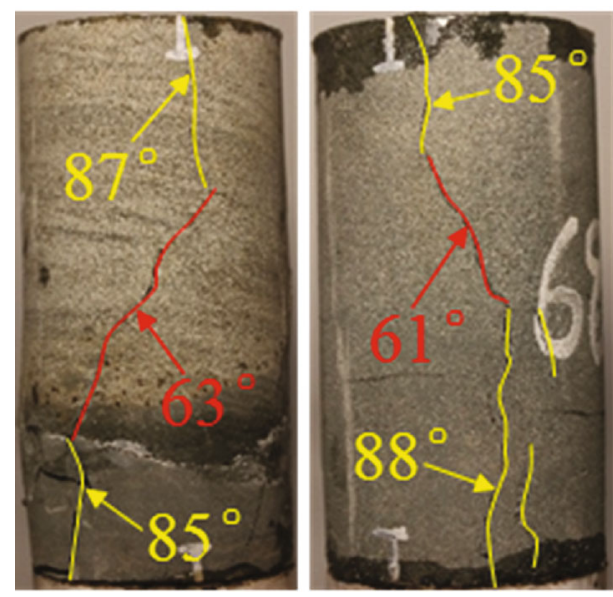

(d) No. 3 sandstone
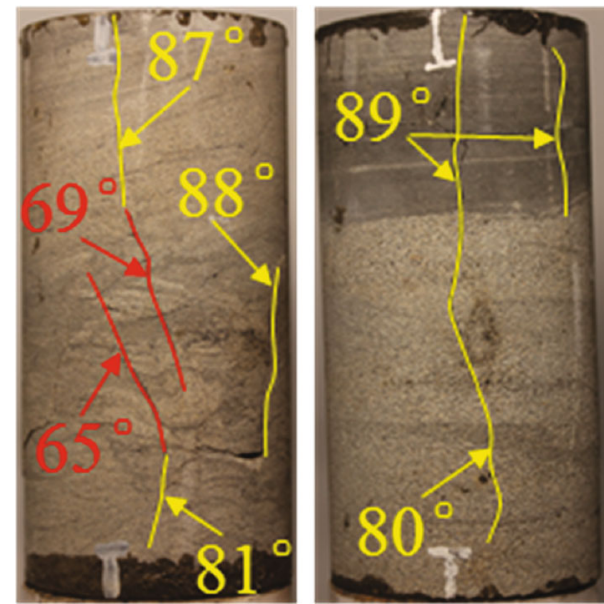

(f) No. 5 sandstone

Figure 11: Continued. 

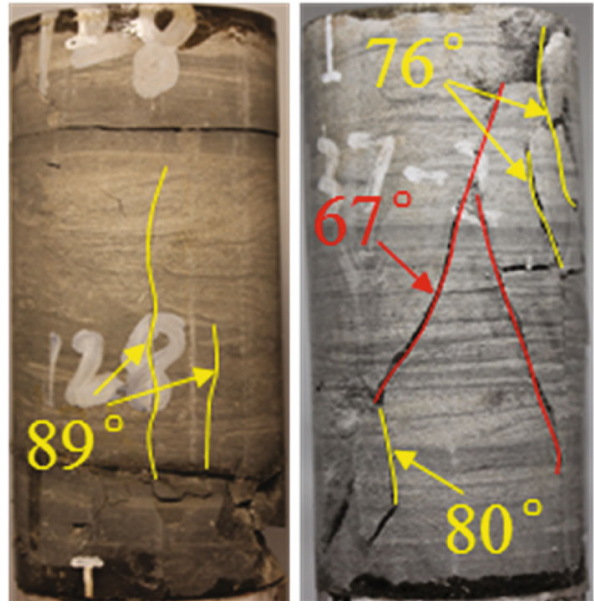

(g) No. 6 sandstone

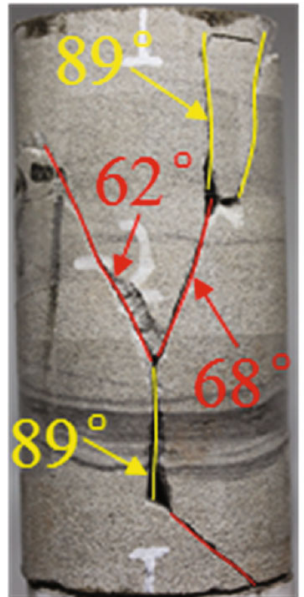

(i) No. 8 sandstone
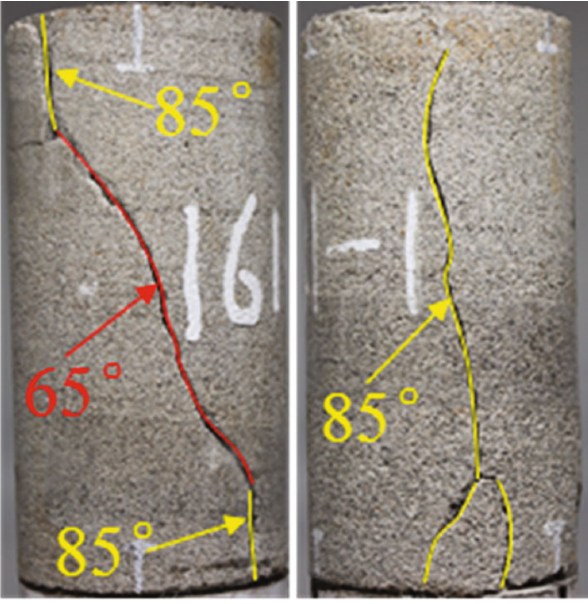

(h) No. 7 sandstone

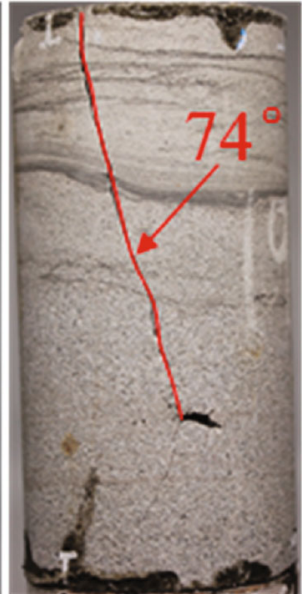

discussed an example of sandstone with pronouncedly negative Poisson's ratio that is due to the fact that the ratio of normal-to-shear compliances of voids in this rock is significantly higher than for the conventional cracks [28, 29]. Therefore, it is possible that the negative Poisson's ratio of sandstone appears at the initial uniaxial compression phase.

At present, the underlying mechanism responsible for the negative Poisson's ratio of rock under uniaxial compressive test is poorly understood. In particular, the mechanism of the negative Poisson's ratio for inorganic crystal material has been revealed that is mainly caused by the rotation or distortion of crystal grains $[30,31]$. This mechanism agrees with studies about the possibility of negative Poisson's ratio in rocks, and some investigations indicate that the microstructures of rocks have great influences on the positive or negative Poisson's ratio. Distortion of $\mathrm{S}_{\mathrm{i}} \mathrm{O}_{2}$ microstructure may be responsible for the negative Poisson's ratio $[32,33]$. When the bond angles and bond lengths between atoms or the spatial distribution of crystal grains meet special structural conditions, the negative Poisson's ratio may occur in rock subjected to uniaxial compression [34, 35]. Based on the X-ray diffraction test of the mineral composition, the main mineral of overlying strata is the quartz, which is composed of $\mathrm{S}_{\mathrm{i}} \mathrm{O}_{2}$. From the microstructure perspective, the rhombi structure model of $\mathrm{S}_{\mathrm{i}} \mathrm{O}_{2}$ was proposed, in which the red atoms represent silicon and the dark blue atoms represent oxygen, as shown in Figure 13. It is obvious that both the horizontal width and vertical length decrease under uniaxial compression, which will result in the negative value of Poisson's ratio. Both the bond lengths and angles between bonds vary in the distortion of the rhombi structure model.

Additionally, the rotation structure model for crystal grains resulting in the negative Poisson's ratio is proposed by Tu and Yang [36] as shown in Figure 14. Assuming the crystal grains are equivalent rectangles with size of $a \times b$, the initial angle between crystal grains is $\theta_{1}$, then becomes $\theta_{2}$ after the uniaxial compression. Then, the $X$-direction and $Y$-direction strains can be calculated, namely,

$$
\varepsilon_{x}=\frac{X_{2}-X_{1}}{X_{1}}=\frac{b \sin \left(\theta_{2} / 2\right)+a \cos \left(\theta_{2} / 2\right)-b \sin \left(\theta_{1} / 2\right)-a \cos \left(\theta_{1} / 2\right)}{b \sin \left(\theta_{1} / 2\right)+a \cos \left(\theta_{1} / 2\right)},
$$




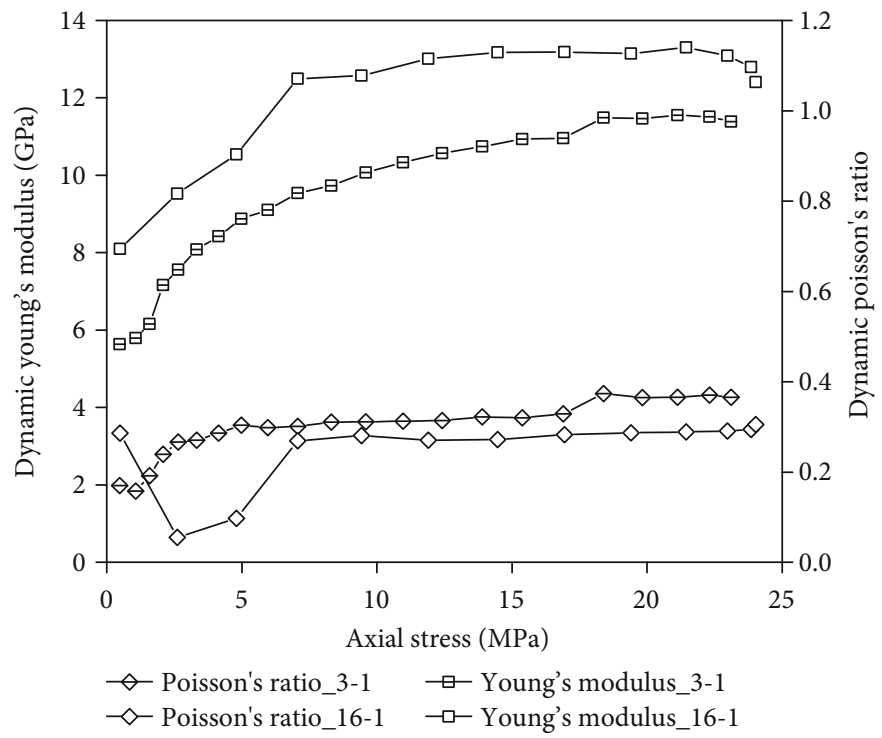

(a) No. 1 sandstone

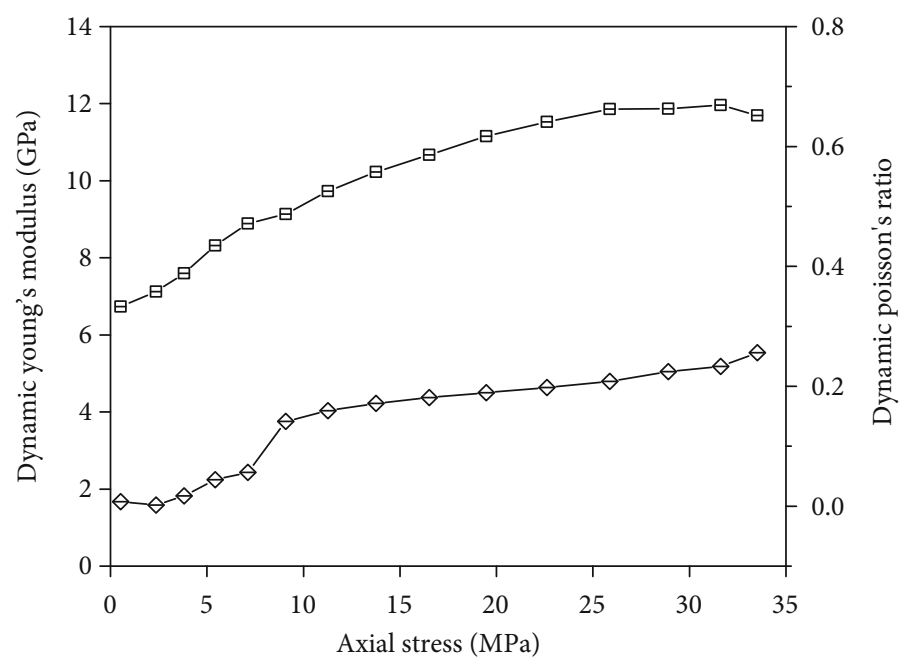

$\diamond$ Poisson's ratio_33-2

- - Young's modulus_33-2

(b) No. 2 sandstone

Figure 12: Continued. 


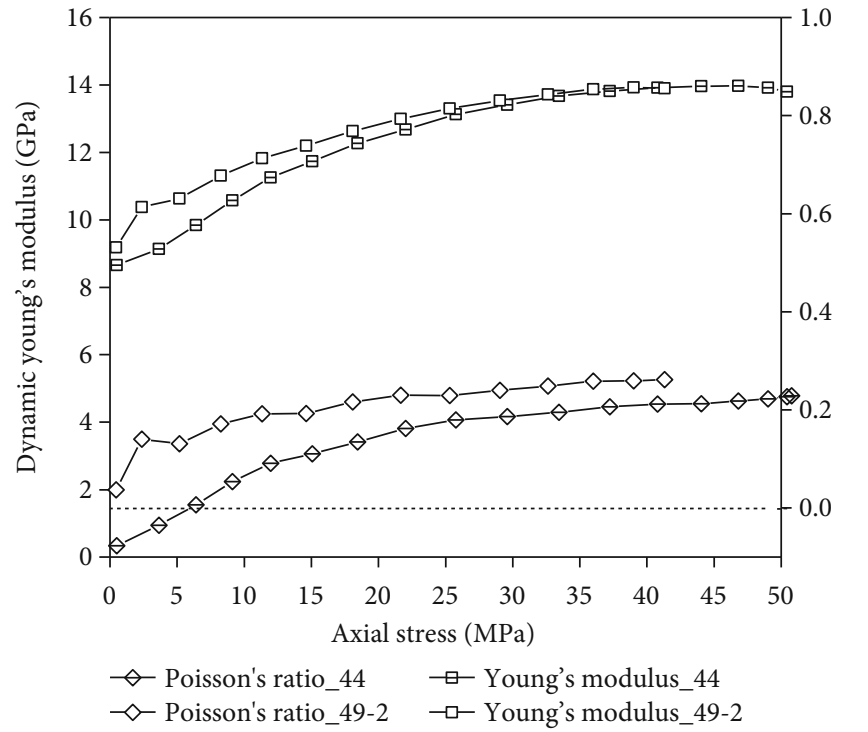

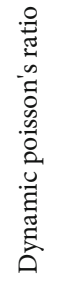

(c) Mudstone

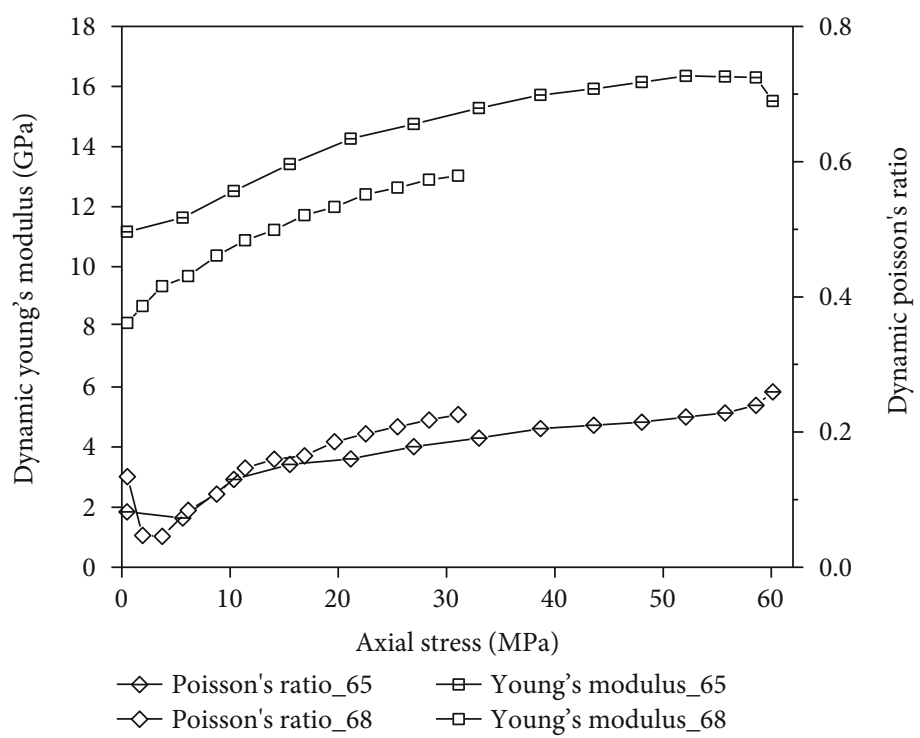

(d) No. 3 sandstone

FIgURE 12: Continued. 


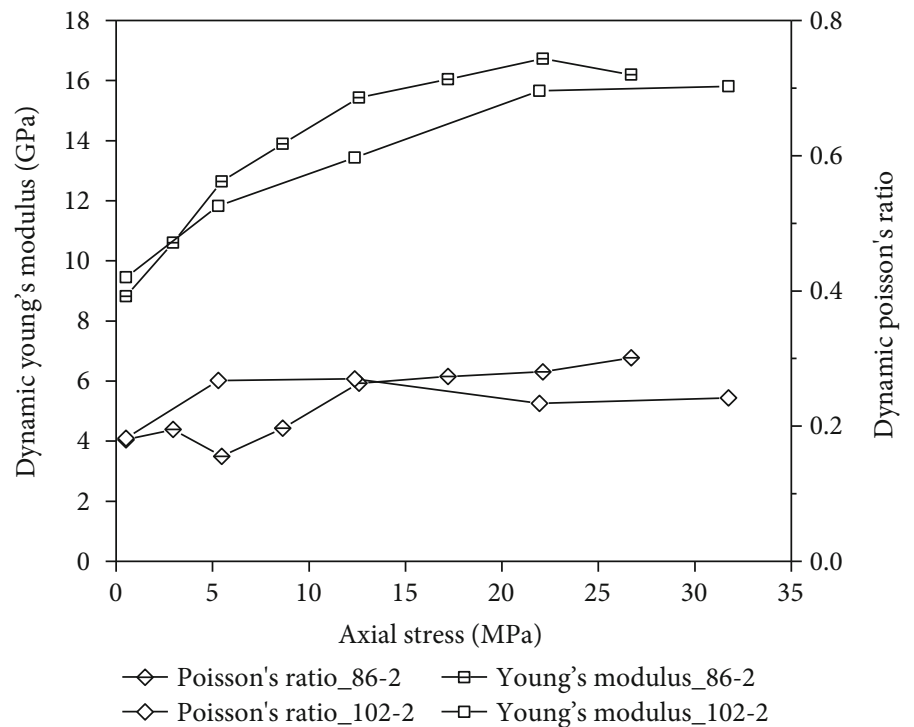

(e) No. 4 sandstone

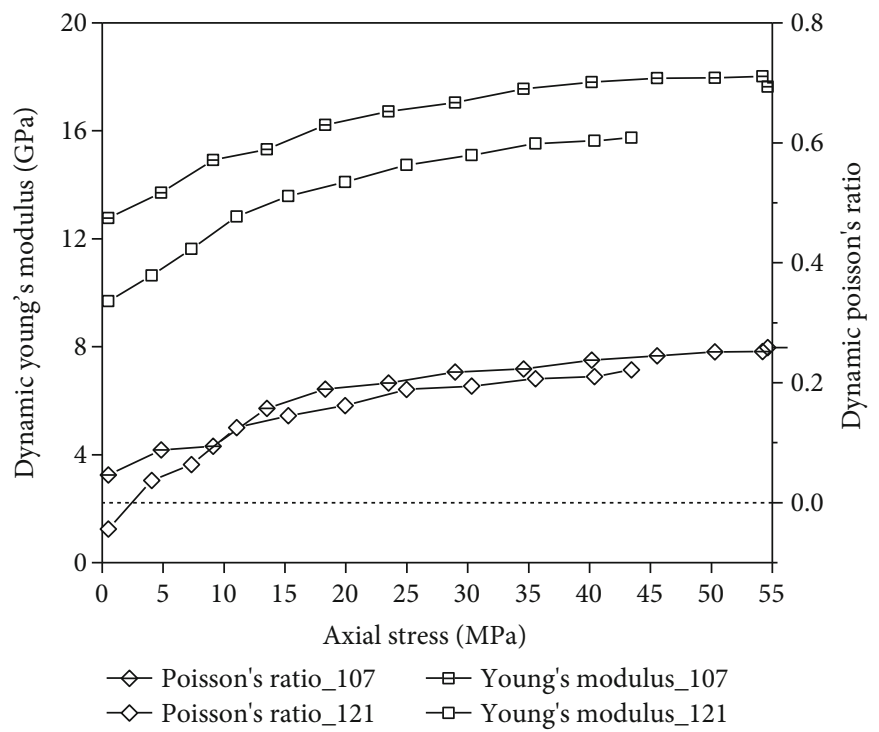

(f) No. 5 sandstone

Figure 12: Continued. 


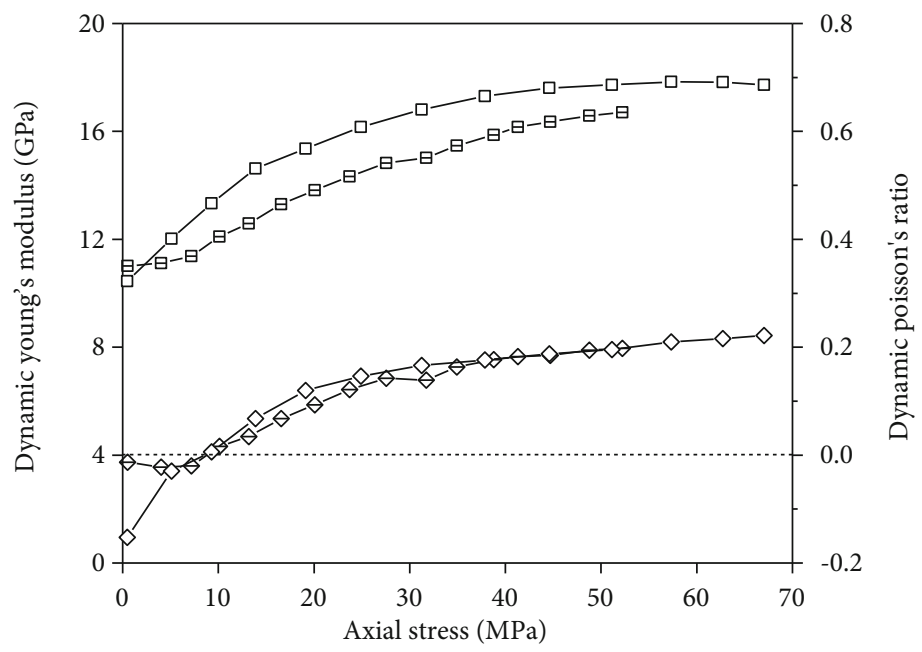

$\checkmark$ Poisson's ratio_128 $\rightarrow$ Yong's modulus_128

$\checkmark$ Poisson's ratio_137-2 $\rightarrow-$ Yong's modulus_137-2

(g) No. 6 sandstone

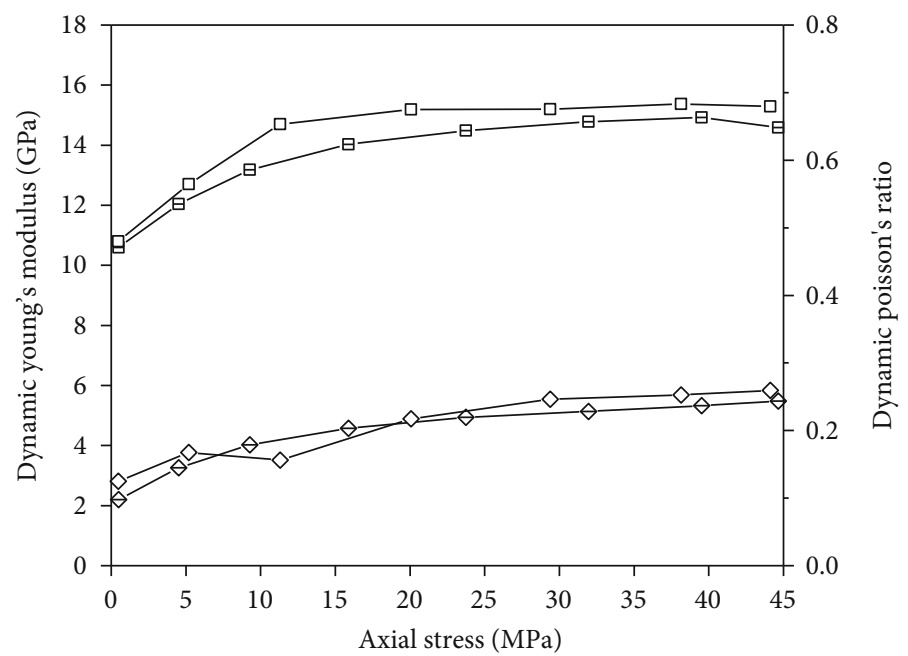

$\checkmark$ Poisson's ratio_161-1 $\rightarrow$-Young's modulus_161-1

$\checkmark$ Poisson's ratio_181-1 $-\square$ Y Young's modulus_181-1

(h) No. 7 sandstone

Figure 12: Continued. 


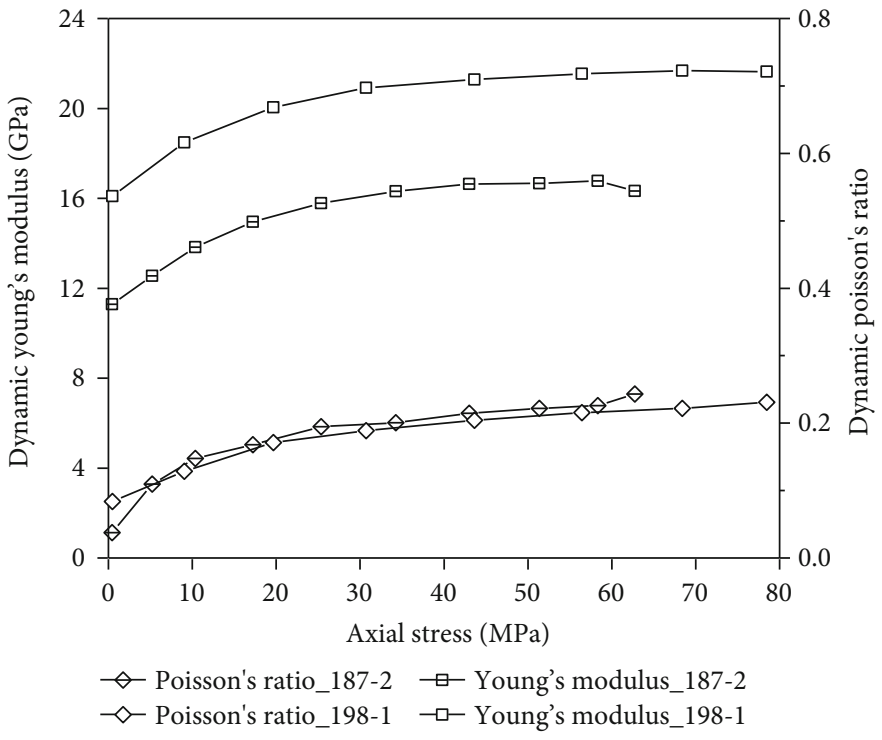

(i) No. 8 sandstone

FIgURE 12: Variation of Young's modulus and Poisson's ratio during loading.
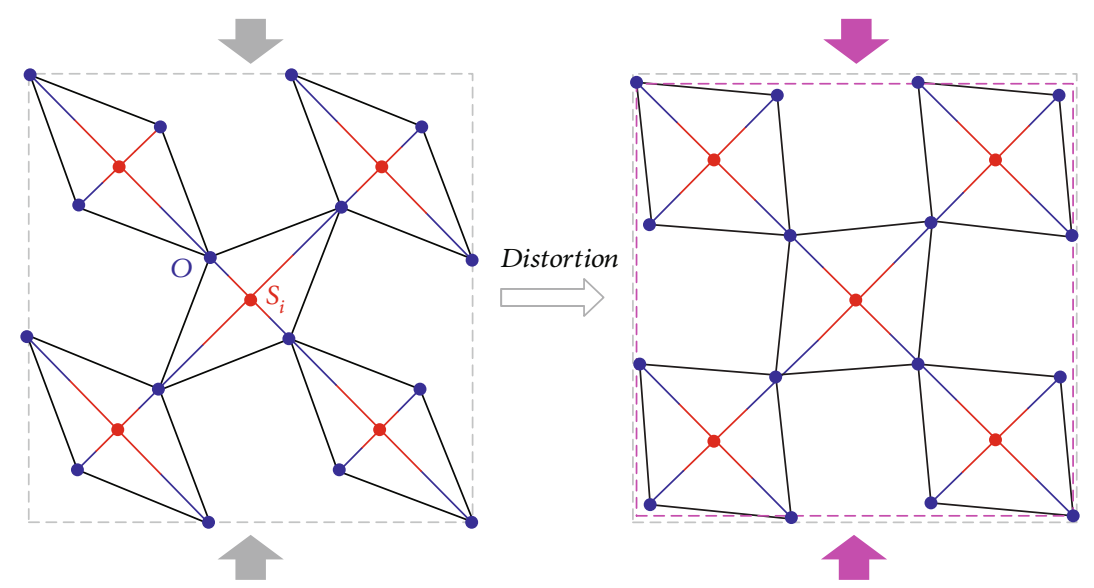

FIgURE 13: Rhombi structure model of $\mathrm{S}_{\mathrm{i}} \mathrm{O}_{2}$ and distortion mechanism of negative Poisson's ratio (modified from [32]).
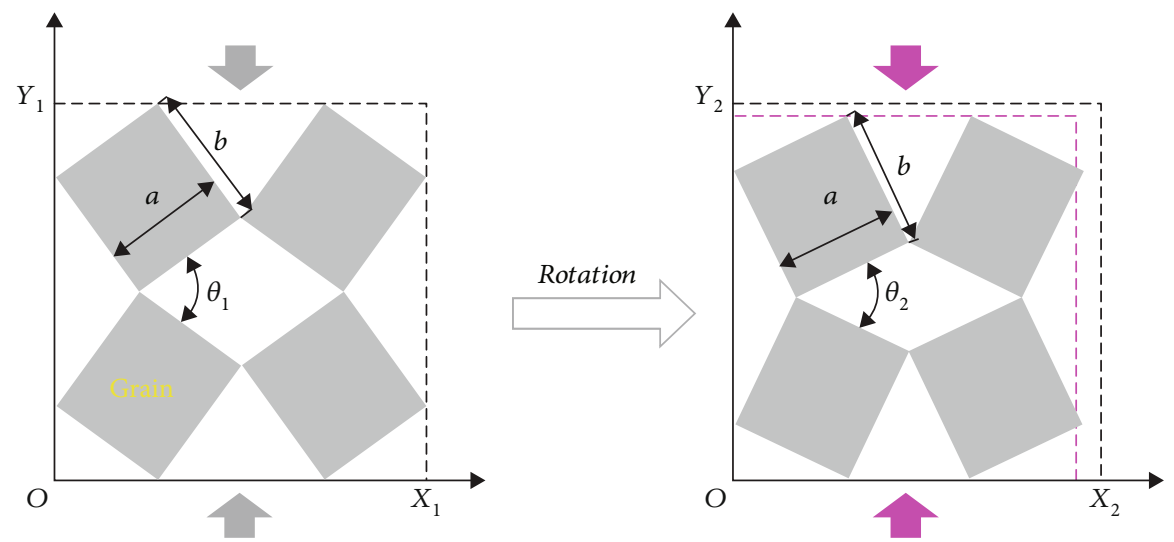

FIGURE 14: Crystal grains structure model and rotation mechanism of negative Poisson's ratio (modified from [36]). 


$$
\varepsilon_{y}=\frac{Y_{2}-Y_{1}}{Y_{1}}=\frac{a \sin \left(\theta_{2} / 2\right)+b \cos \left(\theta_{2} / 2\right)-a \sin \left(\theta_{1} / 2\right)-b \cos \left(\theta_{1} / 2\right)}{a \sin \left(\theta_{1} / 2\right)+b \cos \left(\theta_{1} / 2\right)} .
$$

The Poisson's ratio can be obtained by

$\mu=-\frac{\varepsilon_{x}}{\varepsilon_{y}}=-\frac{\left(a \sin \left(\theta_{1} / 2\right)+b \cos \left(\theta_{1} / 2\right)\right)\left(b \sin \left(\theta_{2} / 2\right)+a \cos \left(\theta_{2} / 2\right)-b \sin \left(\theta_{1} / 2\right)-a \cos \left(\theta_{1} / 2\right)\right)}{\left(b \sin \left(\theta_{1} / 2\right)+a \cos \left(\theta_{1} / 2\right)\right)\left(a \sin \left(\theta_{2} / 2\right)+b \cos \left(\theta_{2} / 2\right)-a \sin \left(\theta_{1} / 2\right)-b \cos \left(\theta_{1} / 2\right)\right)}$.

According to the Eq. (5), when the initial angle between crystal grains is greater than $90^{\circ}\left(\theta_{1}>90^{\circ}\right)$, the Poisson's ratio is positive under the vertical compression, but the Poisson's ratio will become negative when the initial angle between crystal grains is smaller than $90^{\circ}$ $\left(\theta_{1}<90^{\circ}\right)$. The minimum value of Poisson's ratio is -1 when the crystal grains are square, namely, $a=b$. Therefore, the microstructures of rock, especially the angle between crystal grains, may be responsible for the negative value of Poisson's ratio.

\section{Conclusions}

(1) Overall, axial and radial $P$ wave velocities of sandstones are positively correlated to the buried depths, and the circumferential anisotropy in most rock layers is not obvious. Axial P wave velocity is obviously greater than the radial wave velocity due to the effect of stratifications. Shear and split failure occur in most rock samples after compression, and most shear failure cracks appear in the middle of the rock specimens. The average angles between the sandstone failure plane and the minimum and maximum wave directions are $35.8^{\circ}$ and $63.3^{\circ}$, respectively

(2) The axial $\mathrm{P}$ wave and $\mathrm{S}$ wave velocities fluctuate greatly at the initial loading phase, and the $\mathrm{P}$ wave velocity increases faster than the $\mathrm{S}$ wave. When the loading is greater than $80 \%$ of the peak stress, the $\mathrm{P}$ wave velocity almost keeps constant, but the $\mathrm{S}$ wave velocity has an obvious decreasing trend, which can be a prediction signal of rock failure. Finally, both $\mathrm{P}$ wave and $S$ wave velocities drop to zero at the peak stress

(3) The Young's modulus and uniaxial compressive strength are positively correlated with the axial $\mathrm{P}$ wave velocity. Furthermore, the dynamic Young's modulus and dynamic Poisson's ratio obtained based on the $\mathrm{P}$ wave and $\mathrm{S}$ wave velocities increase during loading. However, the negative Poisson's ratio occurs during the initial compression stage in some rock specimens, which may be caused by distortion and rotation of special micro/mesorock structures

\section{Data Availability}

The data used to support the findings of this study are included within the article.

\section{Conflicts of Interest}

The authors declare that they have no conflicts of interest.

\section{Acknowledgments}

This study was funded by the National Natural Science Foundation of China (Grant Nos. 52004287 and 41877257), Beijing Outstanding Young Scientist Program (BJJWZYJH01201911413037), and Shaanxi Coal Group Key Project (2018SMHKJ-A-J-03).

\section{References}

[1] D. Gu, "Theory framework and technological system of coal mine underground reservoir," Journal of China Coal Society, vol. 40, pp. 239-246, 2015.

[2] P. Sharma and T. Singh, "A correlation between P-wave velocity, impact strength index, slake durability index and uniaxial compressive strength," Bulletin of Engineering Geology and the Environment, vol. 67, no. 1, pp. 17-22, 2008.

[3] G. Bi, N. Li, and G. Li, "Experimental study on characteristics of wave propagation in media containing intermittent cracks," Chinese Journal of Rock Mechanics and Engineering, vol. 28, pp. 3116-3123, 2009.

[4] A. Kavetsky, G. Chitombo, C. K. McKenzie, and R. Yang, "A model of acoustic pulse propagation and its application to determine_Q_for a rock mass," International Journal of Rock Mechanics and Mining Science and Geomechanics Abstracts, vol. 27, no. 1, pp. 33-41, 1990.

[5] A. Lachouri, N. Doghmane, and M. Benouareth, "Study of rock acoustic characteristics by parametric spectral analysis. Information and Communication Technologies from Theory to Applications," in Proceedings. 2004 International Conference on Information and Communication Technologies: From Theory to Applications, pp. 387-388, Damascus, Syria, 2004.

[6] M. Cai, P. Kaiser, Y. Tasaka, T. Maejima, H. Morioka, and M. Minami, "Generalized crack initiation and crack damage stress thresholds of brittle rock masses near underground excavations," International Journal of Rock Mechanics and Mining Sciences, vol. 41, no. 5, pp. 833-847, 2004.

[7] C. Martin and N. Chandler, "The progressive fracture of Lac du Bonnet granite," International Journal of Rock Mechanics and Mining Science and Geomechanics Abstracts, vol. 31, no. 6, pp. 643-659, 1994.

[8] D. Tkalich, M. Fourmeau, A. Kane, C. Li, and G. Cailletaud, "Experimental and numerical study of Kuru granite under confined compression and indentation," International Journal of Rock Mechanics and Mining Sciences, vol. 87, pp. 55-68, 2016.

[9] C. K. McKenzie, G. Stacey, and M. Gladwin, "Ultrasonic characteristics of a rock mass," International Journal of Rock Mechanics and Mining Science and Geomechanics Abstracts, vol. 19 , no. 1, pp. 25-30, 1982.

[10] C. Sayers, J. G. van Munster, and M. King, "Stress-induced ultrasonic anisotrophy in Berea sandstone," International Journal of Rock Mechanics and Mining Science and Geomechanics Abstracts, vol. 27, no. 5, pp. 429-436, 1990.

[11] C. Sayers, "Orientation of microcracks formed in rocks during strain relaxation," International Journal of Rock Mechanics and Mining Science and Geomechanics Abstracts, vol. 27, no. 5, pp. 437-439, 1990. 
[12] X. Chen and Z. Xu, "The ultrasonic P-wave velocity-stress relationship of rocks and its application," Bulletin of Engineering Geology and the Environment, vol. 76, no. 2, pp. 661-669, 2017.

[13] M. Khandelwal and T. Singh, "Correlating static properties of coal measures rocks with P-wave velocity," International Journal of Rock Mechanics and Mining Sciences, vol. 79, no. 1-2, pp. 55-60, 2009.

[14] E. Yasar and Y. Erdogan, "Correlating sound velocity with the density, compressive strength and Young's modulus of carbonate rocks," International Journal of Rock Mechanics and Mining Sciences, vol. 41, no. 5, pp. 871-875, 2004.

[15] Z. P. MENG, J. C. ZHANG, and J. Tiedemann, "Relationship between physical and mechanical parameters of coal measures rocks and acoustic wave velocity," Chinese Journal of Geophysics, vol. 49, no. 5, pp. 1352-1359, 2006.

[16] N. Barbosa, J. G. Rubino, E. Caspari, and K. Holliger, "Sensitivity of seismic attenuation and phase velocity to intrinsic background anisotropy in fractured porous rocks: a numerical study," Journal of Geophysical Research: Solid Earth, vol. 122, no. 10, pp. 8181-8199, 2017.

[17] J. Zuo, X. Wei, Y. Shi, C. Liu, M. Li, and R. Wong, "Experimental study of the ultrasonic and mechanical properties of a naturally fractured limestone," International Journal of Rock Mechanics and Mining Sciences, vol. 125, article 104162, 2020.

[18] E. Hamdi and Z. Lafhaj, "Microcracking based rock classification using ultrasonic and porosity parameters and multivariate analysis methods," Engineering Geology, vol. 167, pp. 27-36, 2013.

[19] J. Sarout, L. Esteban, C. Delle Piane, B. Maney, and D. Dewhurst, "Elastic anisotropy of opalinus clay under variable saturation and triaxial stress," Geophysical Journal International, vol. 198, no. 3, pp. 1662-1682, 2014.

[20] J. Sarout, E. Cazes, C. Delle Piane, A. Arena, and L. Esteban, "Stress-dependent permeability and wave dispersion in tight cracked rocks: experimental validation of simple effective medium models," Solid Earth, vol. 122, no. 8, pp. 6180-6201, 2017.

[21] R. Thill, T. Bur, and R. Steckley, "Velocity anisotropy in dry and saturated rock spheres and its relation to rock fabric," International Journal of Rock Mechanics and Mining Science and Geomechanics Abstracts, vol. 10, no. 6, pp. 535-557, 1973.

[22] B. Ahrens, M. Duda, and J. Renner, "Relations between hydraulic properties and ultrasonic velocities during brittle failure of a low-porosity sandstone in laboratory experiments," Geophysical Journal International, vol. 212, no. 1, pp. 627-645, 2018.

[23] G. Jiang, J. Zuo, T. Ma, and X. Wei, "Experimental investigation of wave velocity-permeability model for granite subjected to different temperature processing," Geofluids, vol. 2017, Article ID 6586438, 10 pages, 2017.

[24] G. Jiang, J. Zuo, L. Li, T. Ma, and X. Wei, “The evolution of cracks in Maluanshan granite subjected to different temperature processing," Rock Mechanics and Rock Engineering, vol. 51, no. 6, pp. 1683-1695, 2018.

[25] J. Hudson, S. L. Crouch, and C. Fairhurst, "Soft, stiff and servocontrolled testing machine," Engineering Geology, vol. 6, no. 3, pp. 155-189, 1972.

[26] Y. Chen, J. Zuo, B. Guo, and W. Guo, "Effect of cyclic loading on mechanical and ultrasonic properties of granite from
Maluanshan Tunnel," Bulletin of Engineering Geology and the Environment, vol. 79, no. 1, pp. 299-311, 2020.

[27] Z. Zhao, H. Xu, J. Wang, X. Zhao, M. Cai, and Q. Yang, “Auxetic behavior of Beishan granite after thermal treatment: a microcracking perspective," Engineering Fracture Mechanics, vol. 231, article 107017, 2020.

[28] V. Zaitsev, A. Radostin, E. Pasternak, and A. Dyskin, "Extracting shear and normal compliances of crack-like defects from pressure dependences of elastic-wave velocities," International Journal of Rock Mechanics and Mining Sciences, vol. 97, pp. 122-133, 2017.

[29] V. Zaitsev and P. Sas, "Effect of high-compliant porosity on variations of $\mathrm{P}$ - and S-wave velocities in dry and saturated rocks: comparison between theory and experiment," Physical Mesomechanics, vol. 7, pp. 37-46, 2004.

[30] J. Grima, A. Alderson, and K. Evans, “An alternative explanation for the negative Poisson's ratios in $\alpha$-cristobalite," in In proceedings of the 4th international materials chemistry conference, pp. 81-87, Dublin, 1999.

[31] C. Smith, J. Grima, and K. Evans, "A novel mechanism for generating auxetic behaviour in reticulated foams: missing rib foam model," Acta Materialia, vol. 48, no. 17, pp. 43494356, 2000.

[32] K. Azzopardi, J. Brincat, J. Grima, and R. Gatt, "Advances in the study of the deformation mechanism of stishovite," Physica Status Solidi (B), vol. 252, no. 7, pp. 1486-1491, 2015.

[33] K. Azzopardi, J. Brincat, J. Grima, and R. Gatt, “Anomalous elastic properties in stishovite,” RSC advances, vol. 5, no. 12, pp. 8974-8980, 2015.

[34] E. Pasternak and A. Dyskin, "Materials and structures with macroscopic negative Poisson's ratio," International Journal of Engineering Science, vol. 52, pp. 103-114, 2012.

[35] U. Wollner, T. Vanorio, and A. Kiss, "The effect of fluid and solid properties on the auxetic behavior of porous materials having rock-like microstructures," International Journal of Solids and Structures, vol. 130-131, pp. 211-219, 2018.

[36] Z. Tu and Q. Yang, "Test research on negative Poisson's ratio of rock mass," Rock and Soil Mechanics, vol. 29, no. 10, pp. 2833-2836, 2008. 